UNIVERSIDADE DE SÃO PAULO

FACULDADE DE ODONTOLOGIA DE RIBEIRÃO PRETO

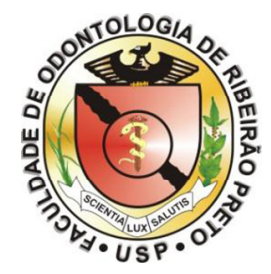

Glauce Crivelaro do Nascimento

\title{
CARACTERIZAÇÃO DAS GELATINASES NO GÂNGLIO TRIGEMINAL DURANTE O DESENVOLVIMENTO DE INFLAMAÇÃO CRÔNICA TEMPOROMANDIBULAR EM RATOS
}

Ribeirão Preto 


\title{
GLAUCE CRIVELARO DO NASCIMENTO
}

\section{CARACTERIZAÇÃO DAS GELATINASES NO GÂNGLIO TRIGEMINAL DURANTE O DESENVOLVIMENTO DE INFLAMAÇÃO CRÔNICA TEMPOROMANDIBULAR EM RATOS}

\author{
Dissertação apresentada à Faculdade de \\ Odontologia de Ribeirão Preto da \\ Universidade de São Paulo, para a obtenção do \\ título de Mestre no Programa de Reabilitação \\ Oral. \\ Área de Concentração: Biologia Oral \\ Orientadora: Profa. Dra. Christie Ramos \\ Andrade Leite-Panissi \\ VERSÃO ORIGINAL
}

Ribeirão Preto 


\section{AUTORIZO A REPRODUÇÃO E DIVULGAÇÃO DO TEOR TOTAL OU PARCIAL DESTE TRABALHO POR QUALQUER MEIO CONVENCIONAL OU ELETRÔNICO, PARA FINS DE ESTUDO E PESQUISA, DESDE QUE CITADA A FONTE.}

Ficha catalográfica elaborada pela Biblioteca Central do Campus USP - Ribeirão Preto

Nascimento, Glauce Crivelaro do

Caracterização das gelatinases no gânglio trigeminal durante o desenvolvimento de inflamação crônica temporomandibular em ratos. Ribeirão Preto, 2011.

79 p. : il. ; $30 \mathrm{~cm}$

Dissertação de Mestrado, apresentada à Faculdade de Odontologia de Ribeirão Preto/USP. Área de Concentração: Biologia Oral.

Orientador: Leite-Panissi, Christie Ramos Andrade

1. Dor Orofacial. 2. Inflamação Temporomandibular. 3. Hiperalgesia Orofacial. 4. Alodinia Mecânica. 5. Metaloproteinases da Matriz. 


\section{FOLHA DE APROVAÇÃO}

\section{Glauce Crivelaro do Nascimento}

Dissertação apresentada à Faculdade de Odontologia de Ribeirão Preto, da Universidade de São Paulo, para obtenção do título de Mestre.

Área de Concentração: Biologia Oral

Aprovado em:

Banca Examinadora:

1) Prof.(a). Dr.(a).:

Instituição:

Julgamento:

Assinatura:

2) Prof.(a). Dr.(a).:

Instituição:

Julgamento:

Assinatura:

3) Prof.(a). Dr.(a).:

Instituição:

Julgamento:

Assinatura: 


\section{DEDICATÓRIA}

Dedico este trabalho,

À Deus, por iluminar meus passos e me proporcionar sabedoria, saúde e proteção necessários para minha caminhada.

À minha mãe, Aparecida Verônica, por estar ao meu lado em todos os momentos, por ser, acima de tudo minha melhor amiga, por me escutar e me aconselhar com tanto carinho e por me proporcionar o amor tão necessário diante dos obstáculos da vida.

Ao meu pai, José Pantalião, por toda a preocupação e carinho que tem comigo, por ter me dado todo o apoio na realização deste mestrado, pelos valiosos conselhos e por ser meu exemplo de dedicação e caráter.

Ao meu irmão, Thiago, por ser minha grande referência desde minha infância, ser o maior incentivador dos meus estudos e por estar sempre ao meu lado, participando de minha vida com tanta preocupação e carinho.

À minha cunhada Deise, pelo tempo despendido na impressão desta dissertação e por ser uma verdadeira irmã para mim, sempre demonstrando carinho, alegria e disposição. Ao meu namorado, Adriano, pelo amor, companheirismo, a paciência e a amizade de todos os momentos e por me fortalecer com conselhos e ajuda na realização de todos os meus sonhos e objetivos.

Sem vocês, nada disso seria possível! 


\section{AGRADECIMENTOS}

À Professora Christie Ramos Andrade Leite-Panissi, por suas palavras sempre sábias, por sua paciência e empenho durante os ensinamentos, e, acima de tudo, por ser uma orientadora preocupada, carinhosa e sempre disposta em ajudar seus orientados.

À Professora Raquel Fernanda Gerlach, por ter cedido seu laboratório para a realização de vários experimentos deste trabalho e pelos seus conselhos e opiniões dedicados com tanta disposição.

Aos professores da banca, pela atenção dispensada na leitura desta dissertação.

À doutoranda Élen Rizzi, pela fundamental colaboração na realização da zimografia.

À Professora Karina Fittipaldi Bombonato Prado, por ter me iniciado na carreira acadêmica com tanta preocupação e atenção e com ensinamentos que levarei por toda a vida.

À Professora Mamie Mizusaki Iyomasa, pelo auxílio no início deste trabalho.

À Professora Maria José Alves Rocha, por ter cedido alguns dos equipamentos de seu laboratório para realização de experimentos deste trabalho.

À Maria Inês e ao José Tadeu, pelo carinho e por toda a ajuda que prestaram à mim durante o mestrado. Obrigada por serem meus segundos pai e mãe!

Ao, Alexandre, pelo apoio e pela torcida em todas as minhas conquistas e à Luciana, pela disposição em sempre me ajudar, me ouvir e me aconselhar, pelas trocas de experiências e pelos momentos alegres e harmoniosos.

Aos meus amigos do laboratório, Alberto, Aline, Amanda, Ana Paula, Eveline, Jardel, Nádia e Priscila, pelos ensinamentos que cada um me passou para que eu pudesse realizar este trabalho, pelo apoio de todos durante meu início neste laboratório e principalmente, pela amizade tão valiosa que ficará sempre em meu coração.

À técnica do laboratório Patrícia Basile, pelo auxílio técnico durante a experimentação deste estudo e pelo convívio agradável no laboratório.

Aos meu amigos que estiveram presentes durante a realização de meu mestrado, Iliana, Juliane, Leonardo, Luciana, Marcelo, Maria Beatriz, Paula Dariana, Paula Pastana, Rayana, Tatiana, Vanessa pela amizade, o carinho e a atenção.

Aos amigos que ingressaram no mestrado comigo, Bruno, Lilian e Yamba. Em especial, à Maidy, pela companhia, amizade e por ter me ensinado a ver a vida com outros olhos, mesmo sem se dar conta disso. 
Aos meus amigos do DAPE, Ana Carolina Fragoso Motta, Ana Paula Godói, Cristiane Ap. Bataglion, Professora Cláudia Helena Lovato e Professora Marilena Chinali Komesu, pelos ensinamentos, pelos conselhos e a amizade sempre presente.

Aos técnicos do Biotério I da FORP, Aline Ap. Ferrarese Tiballi, Antonio Sérgio Ap. Mesca e Antonio Massaro, pelos cuidados com os animais experimentais.

Aos secretários, Regiane de C. Tirado Damasceno, Isabel Cristina Galino Sola, Leandro Marin da Silva, Regiane Cristina Moi Sacilotto, que prestaram inestimável auxílio nos aspectos formais que aqui foram despendidos.

À FAPESP, pelo apoio financeiro que permitiu a realização deste trabalho. 


\section{EPÍGRAFE}

"Aprender é a única coisa de que a mente nunca se cansa, nunca tem medo e nunca se arrepende"

Leonardo da Vinci 


\section{$\underline{\text { RESUMO }}$}

NASCIMENTO, G. C. Caracterização das gelatinases no gânglio trigeminal durante o desenvolvimento de inflamação crônica temporomandibular em ratos. Ribeirão Preto, 2011. 79p. Dissertação (Mestrado em Biologia Oral). Faculdade de Odontologia de Ribeirão Preto, Universidade de São Paulo.

A dor é um importante sintoma que sinaliza danos teciduais ou agentes potencialmente prejudiciais ao organismo, evocando respostas sensoriais e motoras de proteção. A dor orofacial apresenta alta prevalência na sociedade atual, sendo esta condição associada a tecidos duros e moles da cabeça, face, pescoço e a estruturas intraorais. Considerando as dores orofaciais de origem músculo-esquelética, destacam-se àquelas causadas pela Disfunção Temporomandibular (DTM). A DTM apresenta etiologia multifatorial, caracterizada por quadros crônicos envolvendo a região cervical, a musculatura mastigatória e a articulação temporomandibular (ATM). Desde que a inflamação das ATMs é considerada a principal causa da dor em pacientes portadores de DTM, a busca por novas opções terapêuticas para esta disfunção envolve estudos desta articulação, abrangendo aspectos fisiológicos, morfológicos e moleculares. Considerando o processo inflamatório e os aspectos moleculares envolvidos no desenvolvimento desta condição, é possível que as enzimas proteolíticas extracelulares, destacando-se as Metaloproteinases da Matriz (MMPs), as quais estão envolvidas na reabsorção de colágeno e de outras macromoléculas, tenham participação ativa neste processo. Em particular, estudos demonstraram que as MMPs estão envolvidas na modulação da dor neuropática, bem como estão presentes no líquido sinovial de portadores de inflamação da ATM. Sendo assim, o objetivo deste trabalho foi avaliar a influência da administração do Adjuvant de Freund (CFA) intraarticular, bilateralmente nas ATMs de ratos, na sensibilidade mecânica e nociceptiva, bem como avaliar a expressão das MMPs, em particular da MMP-2 e MMP-9, no gânglio trigeminal, nas

diferentes fases de desenvolvimento da inflamação. Os resultados mostraram que a inflamação das ATMs promoveu alodinia mecânica e hiperalgesia orofacial. Em adição, a administração de doxiciclina (inibidor inespecífico das MMPs) reduziu as alterações na sensibilidade mecânica e nociceptiva. A quantificação das MMPs no gânglio trigeminal demonstrou que o início da inflamação promove aumento da MMP-9 (1 e 3 dias), enquanto que nas fases tardias do processo inflamatório acompanha-se o aumento da expressão da MMP-2 (3, 7 e 10 dias).

Palavras Chaves: Dor Orofacial, Inflamação Temporomandibular, Hiperalgesia Orofacial, Alodinia Mecânica, Metaloproteinases da Matriz. 


\section{ABSTRACT}

NASCIMENTO, G. C. Characterization of gelatinases in the trigeminal ganglion during development of chronic temporomandibular inflammation in rats. Ribeirão Preto, 2011. 79p. Dissertação (Mestrado em Biologia Oral). Faculdade de Odontologia de Ribeirão Preto, Universidade de São Paulo.

Pain is an important symptom that signals tissue damage or potentially harmful agents to the body and evokes sensory and motor protection. The orofacial pain is a type of symptoms that appears in high prevalence in modern society. This painful condition is associated with hard and soft tissues of the head, face, neck and intraoral structures. Considering the pain of musculoskeletal origin, we can highlight those caused by temporomandibular dysfunction (TMD). The TMD has a multifactorial etiology, characterized primarily by chronic conditions involving the neck, the chewing muscles and temporomandibular joint (TMJ). Inflammation of the TMJ is considered the main cause of pain in patients with TMD. Thus, the search for new therapeutic options for this disorder involves studies in the TMJ region encompassing physiological, morphological and molecular aspects. Considering the inflammatory process as the main cause of pain present in TMD, it is extremely important to understand the molecular aspects involved in developing this condition. In this context, extracellular proteolytic enzymes, highlighting the metaloproteniases matrix metalloproteinases (MMPs) play major role in the resorption of collagen and other macromolecules. The proteolytic activity of these MMPs is controlled by tissue inhibitors of metalloproteinases (TIMPs), which contribute to the maintenance of metabolic balance and structure of the extracellular matrix. Therefore, the objective of this study was to assess whether the type MMP gelatinases (MMP-2 and MMP-9) of the trigeminal ganglion participate in the development of mechanical allodynia and hyperalgesia in rats orofacial chronic inflammation bilateral TMJ. Our results demonstrated the presence of orofacial hyperalgesia, as well as mechanical allodynia in animals with temporomandibular inflammation induced by CFA and an increase in the expression and activity of gelatinases in the trigeminal ganglion of these animals. Still, there was a decrease in nociceptive orofacial hipersensitivity in animals that received a non-specific inhibitor for MMPs (doxycycline, 30mg/kg/day) for 10 days.

Keywords: Orofacial pain, Temporomandibular inflammation; Orofacial hyperalgesia; Mechanical allodynia; Metalloproteinases. 


\section{LISTA DE FIGURAS}

Figura 1 - $\quad$ Animal na caixa de observação durante teste da formalina orofacial.

Figura 2 - Fotomicrografia de corte histológico do gânglio trigeminal de ratos.

Figura 3 - $\quad$ Média do Limiar de Escape (g) no teste de Von Frey em animais do grupo controle (SAL) e com inflamação temporomandibular (CFA).

Figura 4 - $\quad$ Efeito da administração de formalina 2\% na região orofacial de ratos dos diferentes grupos.

Figura 5 - Zimogramas representativos do gânglio trigeminal de ratos 1, 3, 7 e 10 dias após a injeção bilateral de CFA ou salina $0,9 \%$ (grupo controle) na ATM.

Figura 6 - $\quad$ Quantidade de gelatinases MMP-9 (unidades arbritárias) em gânglio trigeminal de animais com injeção de salina em ATM (controle) e no grupo com inflamação temporomandibular (CFA).

Figura 7 - $\quad$ Quantidade de gelatinases MMP-2 (unidades arbritárias) em gânglio trigeminal de animais com injeção de salina em ATM (controle) e no grupo com inflamação temporomandibular (CFA).

Figura 8 - $\quad$ Fotomicrografias representativas da atividade gelatinolítica em gânglio trigeminal nos períodos de 1, 3, 7 e 10 dias após os animais serem submetidos à injeção de salina $0,9 \%$ (SAL) ou CFA (CFA) nas ATMs.

Figura 9 - Quantificação da porcentagem de área da superfície do gânglio trigeminal coberta por fluorescência verde, caracterizando a atividade gelatinolítica.

Figura 10 - $\quad$ Média do Limiar de Escape (g) no teste de Von Frey em animais que receberam injeção intra-articular de salina e administração de veículo da doxiciclina durante 10 dias (SAL+=VEIC) e injeção intra-articular de salina e administração de doxiciclina durante 10 dias (SAL+DOX).

Figura 11 - Média do Limiar de Escape (g) no teste de Von Frey em animais que receberam injeção intra-articular de CFA e administração de veículo da doxiciclina durante 10 dias (CFA+VEIC) e injeção intra-articular de CFA e administração de doxiciclina durante 10 dias (CFA+DOX).

Figura 12A - Efeito da administração de formalina 2\% na região orofacial de ratos que receberam Salina 0,9\% nas ATMs e administração de doxiciclina durante 10 dias $(\mathrm{SAL}+\mathrm{DOX})$ e de ratos que receberam salina nas ATMs e administração de veículo da doxiciclina durante 10 dias (SAL + VEIC). 
Figura 12B - Efeito da administração de formalina 2\% na região orofacial de ratos que receberam CFA nas ATMs e administração de doxiciclina durante 10 dias $(\mathrm{CFA}+\mathrm{DOX})$ e de ratos que receberam CFA nas ATMs e administração de veículo da doxiciclina durante 10 dias (CFA + VEIC). 


\section{LISTA DE ABREVIATURAS}

\begin{tabular}{|c|c|}
\hline AIDS & Síndrome da Imunodeficiência Adquirida \\
\hline ATM & Articulação Temporomandibular \\
\hline ATP & Adenosina Trifosfato \\
\hline $\mathrm{CaCl}_{2}$ & Cloreto de Cálcio \\
\hline CFA & Completo Adjuvant de Freund \\
\hline CGRP & Gene da Calcitonina \\
\hline DTM & Disfunção Temporomandibular \\
\hline FORM & Formalina \\
\hline IL-17 & Interleucina 17 \\
\hline IL-1及 & Interleucina $1 \beta$ \\
\hline IL-6 & Interleucina 6 \\
\hline MEC & Matriz Extracelular \\
\hline MMPs & Metaloproteinases da Matriz \\
\hline $\mathrm{NaCl}$ & Cloreto de Sódio \\
\hline NMDA & Receptor Ácido-N-Metil-D-Aspártico \\
\hline PFA & Paraformoldeído \\
\hline SAL & Salina \\
\hline SNC & Sistema Nervoso Central \\
\hline SNP & Sistema Nervoso Periférico \\
\hline TIMPs & Inibidores Teciduais de Metaloproteinases da Matriz \\
\hline
\end{tabular}




\section{SUMÁRIO}

RESUMO

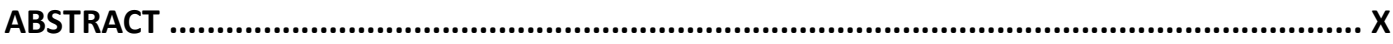

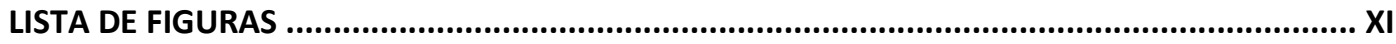

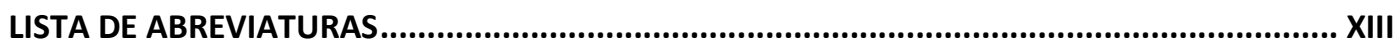

I. INTRODUÇÃO

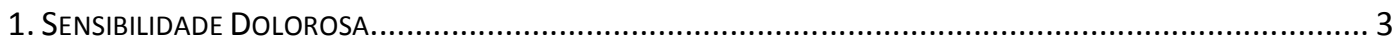

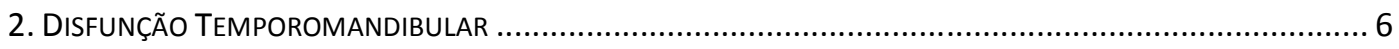

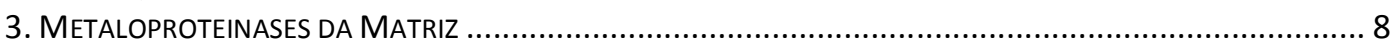

II. PROPOSIÇÃO

III. MATERIAIS E MÉTODOS

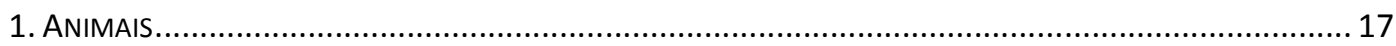

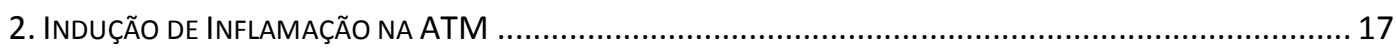

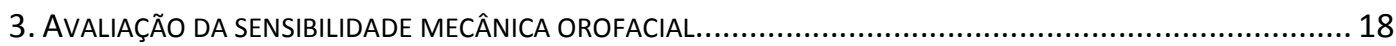

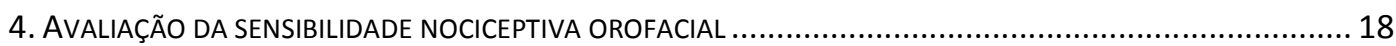

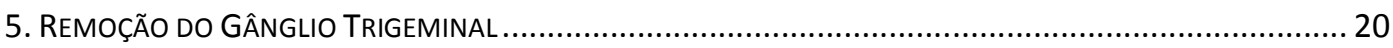

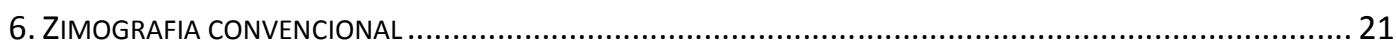

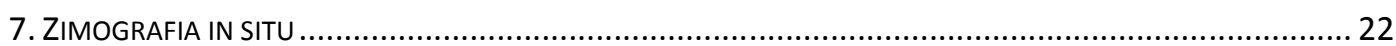

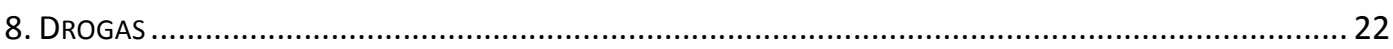

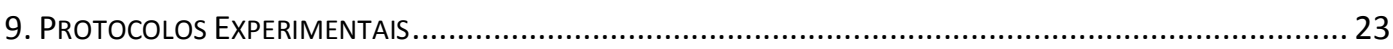

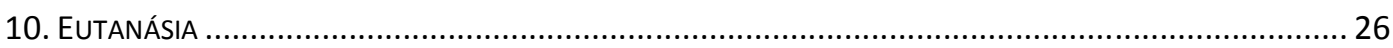

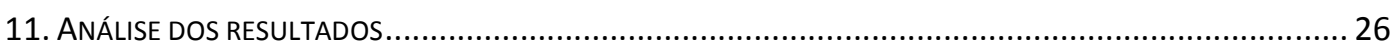

IV. RESULTADOS

1. PROTOCOLO 1: AVALIAÇÃO DA SENSIBILIDADE MECÂNICA E NOCICEPTIVA OROFACIAL EM RATOS

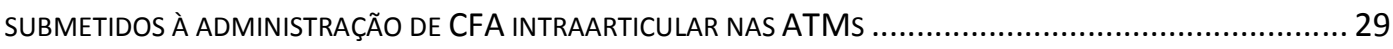

2. PROTOCOLO 2: QUANTIFICAÇÃO DA EXPRESSÃO E DA ATIVIDADE DAS GELATINASES MMP-2 E MMP-9 NO NÚCLEO TRIGEMINAL EM RATOS SUBMETIDOS À INFLAMAÇÃO PERSISTENTE BILATERAL NA ATM ..................... 32

3. PROTOCOLO 3: AVALIAÇÃO DO EFEITO DA ADMINISTRAÇÃO DE UM INIBIDOR INESPECÍFICO DAS METALOPROTEINASES SOBRE A SENSIBILIDADE MECÂNICA E NOCICEPTIVA AGUDA EM RATOS PORTADORES DE

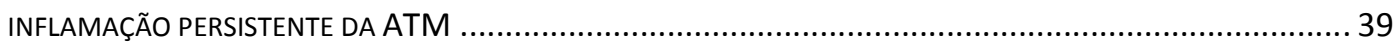

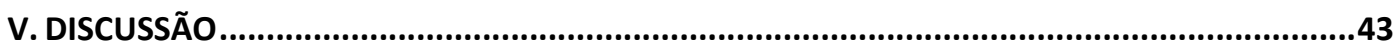

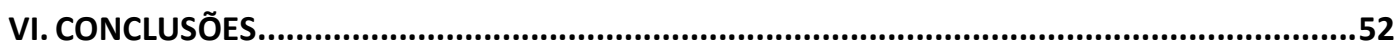

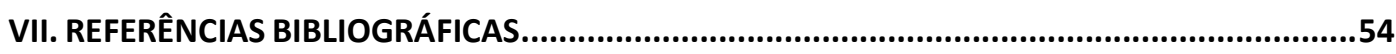




\section{Sensibilidade Dolorosa}

A dor pode ser definida como uma experiência sensorial e emocional desagradável associada a um dano tissular real ou em potencial ou descrita em termos de tais lesões (MERSKEY e BOGDUK, 1994; MILLAN, 1999). A dor representa assim, um importante ganho do ponto de vista evolutivo, pois funciona como mecanismo sinalizador contra danos teciduais ou elementos potencialmente prejudiciais ao organismo, evocando resposta sensorial e motora de proteção (AGUGGIA e cols., 2003; CORTELLI e PIERANGELI, 2003). Desta forma, a dor tem sido considerada composta por: um componente perceptivo-discriminativo, que permite ao indivíduo reconhecer o estímulo como doloroso e localizá-lo em regiões do corpo e o componente aversivocognitivo-motivacional ou reacional, que compreende uma variedade de comportamentos, os quais, por sua vez, envolvem fatores inatos de cada espécie, aprendizagem e memória (BRANDÃO, 1995).

No mecanismo de percepção da dor, os neurônios que respondem preferencialmente a estímulos nocivos são denominados nociceptores. Eles conduzem as informações nociceptivas ao sistema nervoso central (SNC), e seus corpos celulares encontram-se dentro dos gânglios das raízes dorsais, adjacente à medula espinal (CATERINA e JULIUS, 1999) ou no gânglio trigeminal (BASBAUM e JESSEL, 2000). O estímulo nociceptivo inicia-se pelos neurônios de primeira ordem (localizados nos gânglios), os quais se conectam aos neurônios de segunda ordem, do corno dorsal da medula espinal ou núcleo espinal do trigêmeo. Por sua vez, os axônios dos neurônios de segunda ordem cruzam a linha média e ascendem em direção ao córtex, pelo sistema ântero-lateral, principalmente, via trato espinotrigemeotalâmico. As fibras conectam-se então com neurônios talâmicos de terceira ordem, os quais se projetam para o córtex somatossensorial primário e para áreas adjacentes, tais como o sistema límbico, 
conferindo à dor suas propriedades cognitivas e emocionais (PURVES e cols., 2001; AGUGGIA, 2003).

A classificação do processo doloroso é diversificada e depende do critério adotado. Do ponto de vista fisiológico a dor pode ser classificada em três tipos: nociceptiva, inflamatória e neuropática. A dor nociceptiva é um mecanismo de defesa que protege o organismo de um dano potencial ou iminente, sendo produzida, assim como suas conseqüências fisiológicas, pelo funcionamento normal tanto do Sistema Nervoso Central (SNC) quanto do Sistema Nervoso Periférico (SNP). As dores inflamatórias, e principalmente, a dor neuropática, em contraste, são reflexos do funcionamento patologicamente modificado desses dois sistemas (SALTER, 2004). A dor inflamatória é caracterizada pela espontaneidade da sensação dolorosa e pela hiperalgesia (MAMET e cols., 2003), quando há a presença de mediadores inflamatórios. Por outro lado, a dor neuropática é uma condição crônica que ocorre ou persiste após lesão primária ou disfunção no SNC ou SNP (ZIEGLGANSBERGER e cols., 2005).

A condição dolorosa também pode ser classificada de acordo com o critério temporal em aguda ou crônica. A dor aguda é caracterizada pela injúria substancial do tecido com a subseqüente ativação dos nociceptores locais. Apresenta assim, valor biológico adaptativo, uma vez que se desenvolve em resposta a um estímulo potencialmente nocivo. Sendo assim, é um importante sinalizador da integridade de todos os tecidos, iniciando respostas protetoras (SERRA, 1999; AGUGGIA e cols., 2003; CORTELLI e PIERANGELI, 2003). Já a dor crônica não possui esta característica, ela perde a função biológica e caracteriza-se pela sua natureza multidimensional, em que além dos fenômenos neurofisiológicos, estão presentes os aspectos psicológicos, cognitivos, comportamentais, sociais, familiares e vocacionais, os quais podem modular a experiência dolorosa (LOESER e MELZACK, 1999). 
Termos usualmente aplicados em estudos clínicos e experimentais para se referir à sensibilização dos nociceptores durante o processo inflamatório são hiperalgesia e alodinia. De acordo com a Associação Internacional para o Estudo da Dor (IASP), hiperalgesia é a resposta aumentada a um estímulo que normalmente é doloroso, enquanto alodinia é a dor induzida por estímulo que normalmente não provoca dor. Uma adaptação destes conceitos para os modelos experimentais seria que a hiperalgesia representa resposta nociceptiva aumentada a estímulos originalmente nocivos, enquanto a alodinia é caracterizada pela resposta nociceptiva induzida por estímulos originalmente inócuos.

Durante o processo inflamatório ocorre diminuição do limiar para ativação dos nociceptores, responsáveis pelo desenvolvimento de alodinia ou hiperalgesia. Os mediadores inflamatórios originam-se do plasma ou das células. Em particular, os mediadores plasmáticos geralmente são encontrados em formas precursoras que devem ser ativadas por clivagens proteolíticas, a fim de adquirir suas propriedades biológicas. Em contraste, os mediadores celulares normalmente estão armazenados em grânulos intracelulares, que precisam ser secretados, ou são sintetizados em resposta ao estímulo inflamatório (COLLINS, 1999; RYAN e MAJNO, 1977). Dos mediadores inflamatórios plasmáticos, a bradicinina é o mais estudado. Esse peptídeo induz comportamento nociceptivo espontâneo e alodinia (CAMPOS e cols., 1999; SOUZA e cols., 2002), aumenta a permeabilidade vascular (PROUD e KAPLAN, 1988) e induz a migração celular (PASQUALE e cols., 1991; SHIGEMATSU e cols., 1999), entre outras alterações. Alguns estudos demonstraram que o receptor para bradicinina B1 também é importante para a resposta nociceptiva. Dentro deste contexto, camundongos deficientes dos receptores B1 apresentam hipoalgesia no teste da placa quente (temperatura entre 52 e $55^{\circ} \mathrm{C}$ ), inibição do comportamento nociceptivo induzido pela capsaicina ou pela formalina (PESQUERO e cols., 2000). 
Considerando especificamente a dor orofacial, esta sintomatologia aparece com alta prevalência, estando presente em até $86 \%$ da população ocidental. Embora possa ocorrer em qualquer idade, é mais comum entre indivíduos de 13 a 35 anos e quatro vezes mais prevalente em mulheres do que em homens (CARLSSON e DEBOEVER, 2000). A dor de origem orofacial inclui condições dolorosas associadas aos tecidos duros e moles da cabeça, face, pescoço e todas as estruturas intra-orais. A faixa de diagnóstico inclui cefaléias, dores músculo-esqueléticas, dores neurogênicas, dores psicogênicas e dores devidas às doenças graves, tais como câncer e síndrome da imunodeficiência adquirida (AIDS) (MACFARLANE e cols., 2002). Dentre as dores músculo-esqueléticas, podem-se destacar àquelas causadas pela disfunção temporomandibular (DTM).

\section{Disfunção Temporomandibular}

Com relação à DTM, esta disfunção possui origem multifatorial caracterizada por quadros agudos ou, principalmente, crônicos. Os fatores mais comumente relacionados são: modificações da oclusão dentária, fatores emocionais, ausências dentárias, mastigação unilateral e hábitos parafuncionais. Normalmente, um único fator não é responsável pelo desencadeamento da DTM, mas sim, a associação entre eles (OKESON, 1992). A musculatura mastigatória, a articulação temporomandibular (ATM) e a região cervical compõem as estruturas envolvidas na sintomatologia desta desordem (FAVERO, 1999; COSTA e cols., 2004).

A ATM trata-se de uma articulação sinovial formada pelo côndilo mandibular, a qual se encaixa na fossa mandibular do osso temporal. Separando esses dois ossos está o disco articular, interposto, que evita o contato direto dessas estruturas (OKESON e cols., 1998). As superfícies articulares das ATMs são cobertas com tecido conjuntivo denso fibroso e sem cartilagem hialina (DUBRUL, 1980). Essa é uma característica 
importante, pois o tecido conjuntivo fibroso tem maior capacidade de auto-reparação do que a cartilagem hialina. Desta maneira, o tratamento das condições artríticas das ATMs pode ser diferente de outras articulações sinoviais (MEIKEL, 1992). A cápsula articular é um invólucro de tecido denso contendo líquido sinovial, distribuído em dois compartimentos, o supradiscal e o infradiscal. Compõem ainda a ATM, ligamentos justa-articulares e extraarticulares. Finalmente, os músculos masseter, temporal, pterigóideos lateral e medial e os das regiões supra e infra-hióideos mobilizam a ATM (VASCONCELLOS, 1989, MADEIRA, 1995).

A inflamação que ocorre na região das ATMs tem sido considerada como a principal causa da dor relatada pelos pacientes portadores de DTM (YAMASAKI e cols., 2008). Essa inflamação pode ocorrer na membrana sinovial (sinovite) e/ou na cápsula (capsulite), podendo resultar de trauma local, infecção ou degeneração, ou ser parte de uma alteração na formação de colágeno ou poliartrite sistêmica, como por exemplo, a artrite reumatóide (LUND e cols., 2002).

Em laboratório, existem muitos modelos animais utilizados para o estudo da inflamação em ATM, tais como: administração intraarticular de Adjuvante Completo de Freund (CFA), de óleo de mostarda, de formalina, de adenosina trifosfato (ATP) ou de glutamato (BEREITER e cols., 2002; IMBE e REN, 1999; LAM e cols., 2005; OLIVEIRA e cols., 2005; ROVERONI e cols., 2001). Na maioria destes modelos, avalia-se a intensidade da sensibilidade nociceptiva, em resposta à indução da inflamação intraaarticular, por meio da emissão de comportamentos aversivos espontâneos, tais como o de coçar a região orofacial (PALISSIER e cols., 2002). Para indução de inflamação crônica, o CFA é considerado um irritante confiável, capaz de produzir inflamação de longa duração após sua injeção local e de gerar dor aguda e de longa duração (YAMASAKI e cols., 2008). Além disso, em estudo comparativo entre os efeitos do CFA e da injeção de formalina, observou-se a indução de maiores reações 
inflamatórias com o uso do CFA (TING e cols., 2007). Em adição, a inflamação das ATMs está associada com dor tecidual profunda, que é geralmente referida para a pele (IWATA e cols., 1999; IMBE e cols., 2001). Esta característica permite acessar a hiperalgesia induzida pela injeção de CFA nas ATMs através da pele facial, sem a necessidade de manipulação invasiva. Também, estudos demonstram que a inflamação da ATM, induzida por administração intraarticular de CFA, promove ativação de células localizadas no complexo espinal trigeminal do tronco encefálico, em particular, nas lâminas superficiais do núcleo espinal caudal (IMBE e cols., 2001).

\section{Metaloproteinases da Matriz}

Considerando a dor de origem inflamatória, estudos têm demonstrado que as macromoléculas da matriz extracelular (MEC) podem participar do desenvolvimento do processo inflamatório. Especificamente, tem sido demonstrado o envolvimento das metaloproteases e das serinoproteases, enzimas proteolíticas extracelulares secretadas localmente pelas células (SORSA e cols., 2004). De fato, evidências mostraram que entre as possíveis proteinases, as metaloproteinases da matriz (MMPs) desempenham papel principal na reabsorção fisiológica do colágeno e de outras macromoléculas durante o desenvolvimento e a remodelação tecidual pós-natal bem como, na reabsorção patológica associada, por exemplo, ao crescimento de tumores malignos, à reabsorção de estruturas na doença periodontal e à destruição de articulações na artrite reumatóide (KRANE, 1994).

As MMPs constituem uma família de mais de 20 metaloenzimas que clivam vários componentes da MEC, incluindo o colágeno intersticial e o da membrana basal, a fibronectina, a laminina e as proteoglicanas, liberando fragmentos com atividades biológicas distintas. Estas MMPs são secretadas como proenzimas latentes e requerem ativação por meio de clivagem proteolítica do domínio amino-terminal rico em cisteína, 
em adição sua atividade depende da presença de zinco. Várias subclasses de MMPs têm sido definidas e agrupadas de acordo com a especificidade ao substrato: colagenases, gelatinases, estromelisinas, MMP tipo membrana (MT-MMPs) e elastases. Entretanto, há grande similaridade estrutural entre os membros de cada família (MCCAWLEY e cols., 2000). Desta maneira, as MMPs colagenases 1, 2 e 3 são as MMP-1, -8 e -13, respectivamente. Estas MMPs degradam as moléculas de colágeno intersticial tipos I, II e III, além de digerirem outras moléculas da MEC. As MMPs gelatinases A (MMP-2) e B (-9) degradam principalmente colágeno desnaturado (gelatinas) e colágeno tipo IV, enquanto as MMPs estromelisinas 1 e 2 (MMP-3 e -10) podem degradar fibronectina e proteoglicanas (PEREIRA e cols., 2006).

A atividade proteolítica das MMPs é primariamente controlada pelos inibidores de metaloproteinases teciduais (TIMPs). Estes inibidores são pequenas proteínas que bloqueiam a atividade das MMPs ligando-se ao sítio de zinco altamente conservado. Esta ação inibitória é seletiva, reversiva e ocorre de maneira balanceada. A regulação coordenada entre TIMPs e MMPs direciona a clivagem e a liberação de fatores de crescimento importantes e também de receptores de superfície celular (CHANG e WERB, 2001). A expressão dos TIMPs é observada durante a remodelação tecidual fisiológica, contribuindo para a manutenção do equilíbrio metabólico e estrutural da MEC. Alterações na homeostasia entre as MMPs e TIMPs têm sido identificadas em doenças associadas com a remodelação não controlada da MEC, como artrite, câncer, doenças cardiovasculares, nefrites, desordens neurológicas e fibroses, conseqüentemente, há maior degradação da MEC (NAGASE e WOESSNER, 1999; STAMENKOVIC, 2000). O TIMP do tipo 1 (TIMP-1) e do tipo 2 (TIMP-2) representam membros bem caracterizados desta família de inibidores e apresentam atividade inibitória contra as formas ativas de toda a família de MMPs (HOWARD, 1991; FOLGUERAS, 2004). 
A MMP-9 e MMP-2 são as duas metaloproteinases mais estudadas na literatura. Além disso, elas parecem ser as duas MMPs mais expressas no sistema nervoso (DZWONEK e cols., 2004; KACZMAREK e cols., 2002), sendo encontradas na matriz extracelular, líquor e soro. Estas duas gelatinases são ativadas por outras proteases. Por exemplo, a MMP-9 é ativada pela plasmina, a MMP-3 e a MMP-2 são ativadas pela MMP-14. Ainda, enquanto a MMP-2 é expressa constitutivamente em muitos tecidos, a MMP-9 é altamente induzível por distintos processos fisiológicos ou patológicos (MURPHY e WILLENBROCK, 1995), tais como a resposta inflamatória (GAUDIN e cols., 1997).

As MMPs também estão envolvidas nos processos de inflamação e remodelação tecidual associadas à várias doenças neurodegenerativas (KAWASAKI e cols., 2008). Elas são expressas em diversas regiões do cérebro, especialmente em condições patológicas, nas quais as células gliais, bem como, células inflamatórias formam os principais substratos para a atividade destas proteases. Foi observado que em caso de isquemia cerebral em ratos e camundongos, a expressão e a ativação da MMP-2 foi localizada em neurônios, células gliais e no endotélio; enquanto que a MMP-9 foi encontrada em níveis elevados em neurônios e células gliais, bem como em feixes de fibras mielinizadas e a MMP-3, localizada em neurônios (YONG e cols., 2001). Duas estruturas encefálicas estudadas em grande parte dos trabalhos, no que se refere à expressão de MMPs, são o cerebelo e o hipocampo. Dentro deste contexto, utilizando a técnica de zimografia, VAILLANT e cols. (1999), observaram baixos níveis de MMP-9 em cerebelos de ratos adultos e níveis mais altos de MMP-2 nesta estrutura. Neste estudo, observou-se que enquanto a MMP-2 parece ter, em sua maioria, origem glial, as MMP-9 parecem ser expressas principalmente pelos neurônios hipocampais.

Considerando que grande parte da dor orofacial é de origem inflamatória, é possível que as MMPs participem ativamente dos processos dolorosos orofaciais. De 
fato, é bem fundamentado na literatura que as MMPs são as principais responsáveis pela quebra do colágeno durante a destruição tecidual periodontal devido à resposta inflamatória. Assim, fibroblastos gengivais, queratinócitos, macrófagos residentes e leucócitos polimorfonucleares são capazes de expressar MMPs -1, -2, -3, -8, -9, citocinas inflamatórias e fatores de crescimento que regulam a transcrição das MMPs (NAVARRO, 2006). Corroborando estes achados, pacientes com periodontite apresentaram níveis significantemente maiores de MMP-2 e MMP-9 que indivíduos saudáveis, com decréscimo da quantidade de gelatinases após o tratamento periodontal (BIRKEDAL-HANSEN, 1993). Em adição, as concentrações de MMP-9 encontram-se aumentadas no fluido crevicular gengival de pacientes com periodontite crônica generalizada e de pacientes com gengivite; o que sugere que esta enzima pode estar envolvida também no complexo processo de destruição tecidual que ocorre nestes processos inflamatórios (FIGUEREDO e cols., 2003).

Ainda, com relação à dor orofacial, a ativação das MMPs -2 e -9 também foi demonstrada como tendo função fundamental na destruição da dentina por lesões de cárie, principalmente nos casos de lesão da superfície radicular, onde evidências indicam que as MMPs são necessárias para remover a matriz orgânica dentinária (SOUZA e cols., 2003).

Com relação à dor orofacial de origem não odontogênica, em indivíduos portadores de DTM observou-se aumento significativo da concentração de um subtipo de MMP (MMP-3) no líquido sinovial da ATM quando comparado com indivíduos saudáveis. Considerando que neste estudo não foi encontrada correlação entre a concentração de MMP-3 e a morfologia da ATM, é possível que esta metaloproteinase esteja envolvida no processo inflamatório observado na ATM (ISHIMARU e cols., 2000). De fato, em processos inflamatórios articulares, as citocinas inflamatórias 
estimulam a síntese de MMPs, promovendo alteração do equilíbrio entre as MMPs e os TIMPs, resultando em degradação da matriz colagenosa (SHINMEI e cols., 1989).

Sendo a cartilagem articular da ATM composta predominantemente por fibrocartilagem, com grande quantidade de fibras colágenas, as MMPs exercem importante papel nas desordens da ATM, uma vez que as enzimas gelatinases (colagenase tipo IV) degradam os colágenos tipo IV, V, VII e a elastina. Além disso, a gelatinase-A (MMP-2) e a gelatinase-B (MMP-9), presentes no côndilo mandibular, estão intimamente relacionadas aos processos inflamatórios locais. Nesta perspectiva, foi demonstrada correlação entre a presença da MMP-2 no líquido sinovial de pacientes com DTMs e os achados radiográficos indicando degeneração do disco e da cartilagem articular (MIZUI, 2001).

Ampliando as funções das MMPs, recentemente foi demonstrado o envolvimento destas proteinases na modulação da dor neuropática (KAWASAKI e cols., 2008). Neste estudo, a administração aguda ou prolongada de um inibidor não específico das MMPs (GM6001) reduziu significantemente a alodinia mecânica promovida por injúria de um nervo espinal. Possivelmente, as MMPs participam do desenvolvimento da dor neuropática promovendo desmielinização devido degradação da proteína mielínica básica no SNC (CHANDLER e cols., 1995). Corroborando esta hipótese, em camundongos knockout para MMP-9 a desmielinização não ocorreu mesmo após 10 dias da lesão do nervo ciático (CHATTOPADHYAY e cols., 2007).

As moléculas encontradas durante a inflamação temporomandibular podem ser utilizadas como marcadores do desenvolvimento das DTMs, e a identificação desses marcadores pode levar ao melhor esclarecimento sobre as condições que envolvem as dores de origem orofaciais, bem como o desenvolvimento de novas terapias para o tratamento da dor de origem orofacial. Sendo assim, a avaliação de metaloproteinases 
no sistema trigeminal e no desenvolvimento da dor durante a DTM pode ser importante para o compreendimento das bases moleculares envolvidas nesta patogênese. 
II. PROPOSIÇÃO 
Fundamentado na literatura apresentada, o objetivo deste trabalho foi avaliar se a administração intraarticular bilateralmente nas ATMs de ratos de Adjuvant Completo de Freund (CFA) promove alteração da sensibilidade mecânica e da sensibilidade nociceptiva orofacial, bem como, caracterizar a expressão das MMPs, em particular das MMP-2 e MMP-9, no gânglio trigeminal, durante o desenvolvimento da inflamação intraarticular.

Para isto, tivemos os seguintes objetivos específicos:

1. Avaliar se a inflamação bilateral da ATM promove modificação da sensibilidade mecânica orofacial.

2. Avaliar se a inflamação bilateral da ATM altera a sensibilidade nociceptiva orofacial, por meio do uso do teste da formalina.

3. Avaliar se durante o desenvolvimento da inflamação da ATM há alteração da expressão das gelatinases, especificamente da MMP-2 e MMP-9, no gânglio trigeminal em diferentes estágios, 1, 3, 7 e 10 dias após a administração do CFA.

4. Detectar atividade gelatinolítica no gânglio trigeminal por meio da zimografia in situ com substrato fluorogênico em ratos portadores de inflamação intraarticular da ATM bilateral.

5. Analisar se o tratamento sistêmico com um inibidor não seletivo das MMPs interfere na sensibilidade mecânica e nociceptiva de ratos portadores de inflamação temporomandibular. 


\section{MATERIAIS E MÉTODOS}




\section{Animais}

Foram utilizados ratos Wistar machos (250 a 300 gramas) cedidos pelo Biotério Central do Campus de Ribeirão Preto. Os animais são mantidos em caixas acrílicas coletivas (4 ratos por caixa) com $1353 \mathrm{~cm}^{2}$ de área, em ambiente com temperatura controlada $\left(24^{\circ} \mathrm{C} \pm 1^{\circ} \mathrm{C}\right) \mathrm{e}$ ciclo claro-escuro de 12 horas (ciclo claro se iniciando às 7 horas), com água filtrada e comida ad libitum.

Todos os protocolos experimentais foram realizados de acordo com os regulamentos e cuidados na utilização de animais de laboratório, conforme a Sociedade Brasileira de Neurociências e Comportamento, e foram aprovados pela Comissão de Ética para o Uso de Animais da Prefeitura do Campus Administrativo de Ribeirão Preto/USP (processo no. 09.1.371.53.0).

\section{Indução de Inflamação na ATM}

Para indução de inflamação crônica da articulação temporomandibular, os ratos foram inicialmente anestesiados por meio da injeção intramuscular de cetamina a 10\% (75 $\mathrm{mg} / \mathrm{Kg})$ e xilasina $4 \%(10 \mathrm{mg} / \mathrm{Kg})$ para permitir a administração de Adjuvante Completo de Freund (CFA) intraarticular, bilateralmente. A diluição utilizada foi de 1:1 (óleo/salina) no volume $0,1 \mathrm{~mL}$ de CFA na região da ATM, bilateralmente. Para a injeção foi utilizada uma agulha calibre $30 \mathrm{G}^{1} \frac{1}{2}$ acoplada a uma seringa plástica de $1 \mathrm{~mL}$. Para localização das ATMs foi realizada a palpação do arco zigomático e do côndilo mandibular, identificando assim, o local correto da injeção. A agulha foi inserida imediatamente inferior à borda posteroinferior do arco zigomático e avançada em direção anterior até entrar em contato com a borda posterolateral do côndilo (ZHOU e cols., 1999). 


\section{Avaliação da sensibilidade mecânica orofacial}

Para avaliação da sensibilidade mecânica orofacial, foi avaliado o limiar de retirada da cabeça após a aplicação de um estímulo mecânico não nocivo, por meio do uso de um anestesiomêtro digital modelo Von Frey (Insight Instrumentos), o qual faz uso de um filamento com aumento progressivo de força (em gramas). Este estímulo foi aplicado na região das ATMs um dia antes da administração do CFA e 10 dias após a indução da inflamação, em grupos independentes. O limiar de retirada da cabeça foi avaliado em gramas. Para realização dos testes o rato foi submetido a 24 horas de restrição hídrica, e no momento dos testes foi mantido em uma caixa acrílica sem restrição de movimentos por 20 minutos, inicialmente para habituação, e após este período foi oferecida água e realizado o teste com o filamento. Foram realizadas 3 medidas de limiar em cada sessão teste, sendo a média destes 3 valores considerado como o limiar de retirada propriamente dito (WU e cols., 2010).

\section{Avaliação da sensibilidade nociceptiva orofacial}

Para avaliação da sensibilidade nociceptiva orofacial frente a um estímulo nocivo agudo localizado na região orofacial, foi realizado o teste da formalina orofacial em ratos submetidos à administração de CFA ou salina $0,9 \%$ intraarticular bilateralmente nas ATMs.

O teste da formalina orofacial foi realizado 10 dias após o início dos experimentos, ou seja, após a administração de CFA ou salina 0,9 \% intraarticular. Para a realização dos testes os ratos foram habituados à caixa de observação $(30 \mathrm{~cm}$ x $30 \mathrm{~cm}$ x $30 \mathrm{~cm}$ em acrílico transparente), por 20 minutos, e em seguida foram submetidos à breve anestesia inalatória, por meio do uso do halotano para permitir a manipulação e administração de formalina na concentração de $2 \%$ ou solução salina $0,9 \%$ no volume de $50 \mu \mathrm{L}$ (CLAVELOU e cols., 1989). 
A administração foi realizada na região orofacial, unilateralmente, entre o lábio superior e o nariz, na região das vibrissas, tendo como auxílio uma seringa de $1 \mathrm{~mL}$ graduada em $0,01 \mathrm{~mL}$ e uma agulha calibre $30 \mathrm{G}^{1} / 2$. A administração foi realizada o mais breve possível, para que o animal não fosse manipulado por tempo prolongado.

Imediatamente após a administração de formalina $2 \%$ ou solução salina $0,9 \%$, o animal foi colocado na caixa de observação e iniciou-se a observação do comportamento do animal (Figura 1). Foi analisado o tempo gasto pelo animal com o comportamento de coçar a região injetada, em segundos, durante 45 minutos, em 15 blocos de 3 minutos cada. O teste da formalina orofacial é caracterizado por possuir duas fases distintas, fase aguda inicial (0-3 minutos), período silencioso (3-15 minutos) e segunda fase (15-45 minutos) (GRABOW \& DOUGHERTY, 2001). É considerado o pico da segunda fase o $7^{\circ}$ intervalo do teste, ou seja, o período compreendido entre o $21^{\circ}$ e $24^{\circ}$ minuto.

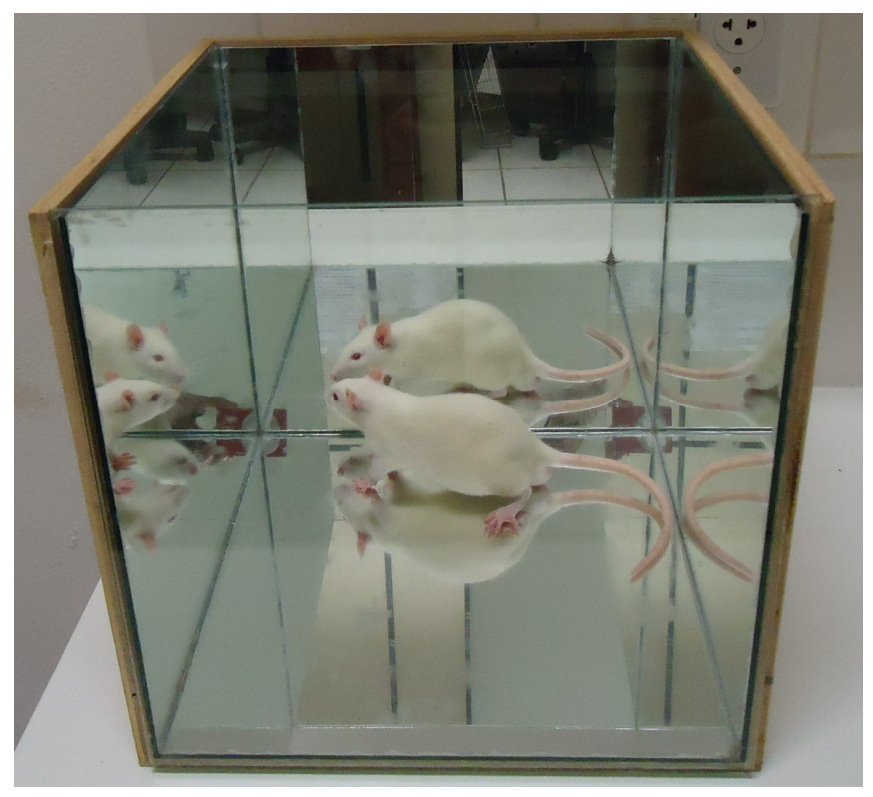

Figura 1: Fotografia representativa de um rato na caixa de observação utilizada para o teste de formalina orofacial. 


\section{Remoção do Gânglio Trigeminal}

Para obtenção do gânglio trigeminal, os ratos foram anestesiados profundamente por meio do uso de uma solução de hidrato de cloral a $10 \%(0,5 \mathrm{ml} / 100 \mathrm{~g}$ de peso corporal $)$ e em seguida foram submetidos à eutanásia, nos períodos de 1, 3, 7 e 10 dias após aplicação de CFA ou solução salina 0,9 \% na ATM. A determinação destes períodos fundamentouse em trabalho anterior, onde foi realizada a quantificação das MMPs 2 e 9 nos gânglios da raiz dorsal em ratos submetidos a injúria do nervo para desenvolvimento de dor neuropática (KAWASAKI e cols., 2008).

Confirmada a eutanásia, foi realizada a remoção dos gânglios trigeminais, os quais foram dissecados e lavados em solução de $\mathrm{NaCl}$ 0,9\% com a finalidade de se retirar grande parte do sangue contido na amostra, reduzindo possíveis interferências nos resultados. Todos os tecidos, após a coleta, foram cortados em pedaços para que as amostras fossem utilizadas para extração e quantificação de proteínas. A Figura 2 apresenta uma fotomicrografia de um gânglio trigeminal obtido em nossos experimentos e corado pela técnica de hematoxilina-eosina, a fim de confirmar a retirada correta do tecido.

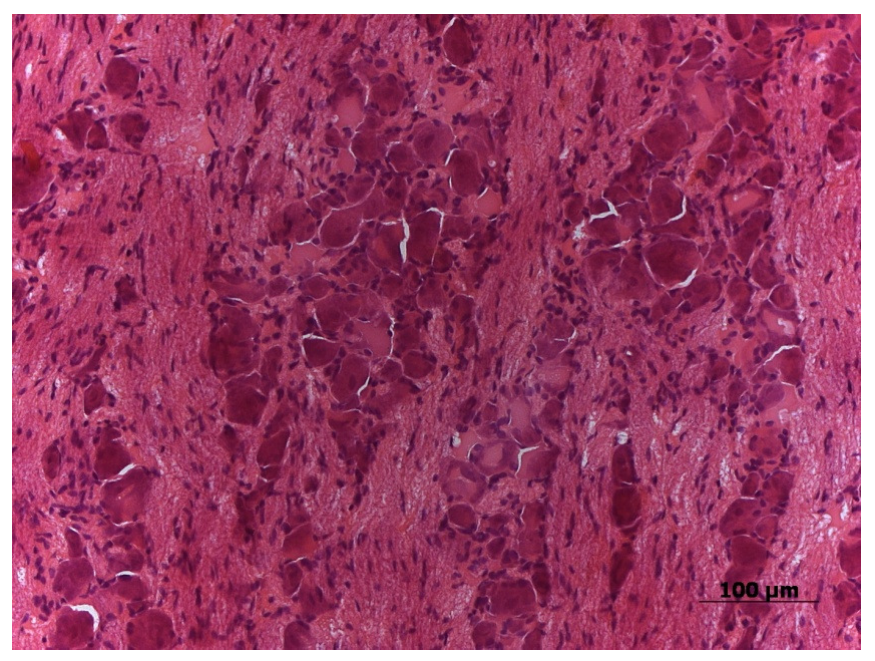

Figura 2: Fotomicrografia de corte histológico longitudinal $(20 \mu \mathrm{m}$ de espessura) de um gânglio trigeminal representativo de rato utilizado em nossos experimentos. (Coloração H.E.; aumento de 20x). Barra: $100 \mu \mathrm{m}$. 


\section{Zimografia convencional}

A zimografia é uma técnica que permite visualizar diferentes isoformas de uma enzima ou das formas pró-enzima e enzima ativa, as quais são muito freqüentes em enzimas proteolíticas extracelulares, como as MMPs.

Para o preparo das amostras do gânglio, foi adicionado $150 \mu \mathrm{L}$ do tampão $\mathrm{CaCl}_{2}$

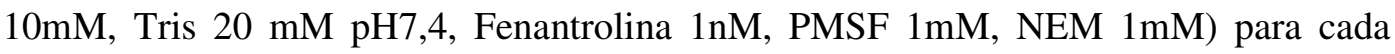
0,05g do tecido. As amostras foram trituradas com o uso do politron e eram colocadas no gelo, mantidas na geladeira por no mínimo 16 horas para ocorrer o processo de extração das proteínas do tecido. Após este período, as amostras foram centrifugadas a $3.000 \mathrm{rpm}$ por 15 minutos, o sobrenadante retirado e armazenado em dois tubos eppendorf devidamente rotulados no freezer a $-20^{\circ} \mathrm{C}$. Um tubo foi utilizado para dosagem de proteínas pelo método de Lowry, necessária para que não houvesse variação da quantidade de proteínas de um animal para outro. O outro tubo foi utilizado para determinar a atividade das metaloproteinases no gel de zimografia. A zimografia foi realizada aplicando-se 30 ug de proteína do extrato obtido do gânglio trigeminal no gel de corrida, contendo polacrilamida a $12 \%$ e gelatina a $0,1 \%$.

Após a corrida, os zimogramas foram submetidos a dois banhos de solução renaturante de Triton $\mathrm{X}-100$ a 2\%. O gel foi incubado em tampão Tris- $\mathrm{CaCl}_{2}$ por 18 horas a temperatura de $37^{\circ} \mathrm{C}$. Em seguida, o gel foi corado pelo corante Comassie Blue G-250 e descorado com uma solução de metanol e ácido acético até a visualização das bandas características da atividade das MMPs: bandas claras contra um fundo azul escuro (devido à coloração da gelatina incorporada ao gel preparado. A avaliação da expressão enzimática foi feita através do software Kodak EDAS290; obtidos os dados, o gel foi colocado em solução de metanol para contração e seco em papel celofane.

As MMPs foram identificadas através de suas massas moleculares $92 \mathrm{kDa}$ para a MMP-9 e 75 kDa, 72 kDa e 64 kDa para as MMPs-2. Após quantificação das bandas 
através do programa, o valor do padrão de cada gel foi dividido pelo valor das bandas do mesmo gel e os dados obtidos foram então avaliados estatisticamente.

\section{Zimografia in situ}

Esta análise foi realizada para verificar o total de atividade gelatinolítica nos tecidos dos grupos de animais deste estudo. Os gânglios foram congelados em Tissue Tek O.C.T. Compound e isopentano e acondicionados em freezer à $-70^{\circ} \mathrm{C}$. Foram feitos cortes longitudinais de $14 \mu \mathrm{m}$ de espessura em criostato e estes cortes foram dispostos em lâminas tratadas com poli-L-Lisina (P8920, Sigma, St. Louis, MO, USA).

Os cortes foram cobertos por substrato DQ-gelatin (E12055, Molecular Probes, Oregon, USA) diluído na concentração de 1:10 em Tris- $\mathrm{CaCl}_{2}(50 \mathrm{~mol}, \mathrm{pH}$ 7,4). Foram aplicados $20 \mu \mathrm{L}$ da DQ em cada corte. As lâminas foram incubadas no interior de uma câmara úmida, escura e a temperatura ambiente por 1 hora. Após a incubação, as lâminas foram lavadas 3 vezes com PBS e em seguida os cortes foram fixados com paraformoldeído a $4 \%$ tamponado (PFA). Houve então nova lavagem, e as lâminas foram montadas com lamínulas para serem visualizadas e fotografadas. Para a quantificação da atividade gelatinolítica foi utilizado o programa Leica Qwin (Leica Imaging Systems Ltda, Cambridge, Inglaterra) em conjunto com um microscópio Leica (Leica DMR), videocâmera (Leica DC300F) e um computador on-line. A quantificação da fluorescência foi feita em pixels por área.

\section{Drogas}

Neste estudo foi utilizado o Adjuvante Completo de Freund na diluição de 1:1 (óleo/salina) no volume de $0,1 \mathrm{~mL}$ para promover a inflamação crônica das ATMs e formalina $2 \%$, no volume de $50 \mu \mathrm{L}$ no teste da formalina orofacial. 
Para realizar o bloqueio inespecífico das metaloproteinases foi utilizado a doxiciclina na dose de $30 \mathrm{mg} / \mathrm{Kg}$ / dia por gavagem (RIZZI e cols., 2009), durante 10 dias, iniciando no primeiro dia da administração do CFA intraarticular nas ATMs. O veículo utilizado foi a água destilada, e o volume administrado foi de $1 \mathrm{~mL}$.

\section{Protocolos Experimentais}

Protocolo 1: Avaliação da sensibilidade mecânica e nociceptiva orofacial em ratos submetidos à administração de CFA intraarticular nas ATMs.

Grupo 1 (n = 8, MEC: SAL): ratos receberam injeção de solução salina 0,9 \% na região das ATMs bilateralmente, e no $10^{\circ}$ dia experimental foi realizado o teste de avaliação da sensibilidade mecânica orofacial.

Grupo 2 ( $\mathrm{n}=8$, MEC: CFA): ratos receberam injeção de CFA na região das ATMs bilateralmente, e no $10^{\circ}$ dia experimental foi realizado o teste de avaliação da sensibilidade mecânica orofacial.

Grupo 3 (n = 8, FORM: SAL+SAL): ratos receberam injeção de solução salina $0,9 \%$ na região das ATMs bilateralmente, e no $10^{\circ}$ dia experimental foi realizado o teste de avaliação da sensibilidade nociceptiva orofacial por meio da administração de solução salina $0,9 \%$ orofacial.

Grupo 4 (n = 8, FORM: SAL+FORM): ratos receberam injeção de solução salina $0,9 \%$ na região das ATMs bilateralmente, e no $10^{\circ}$ dia experimental foi realizado o teste de avaliação da sensibilidade nociceptiva orofacial, pelo teste da formalina.

Grupo 5 (n = 8, FORM: CFA+FORM): ratos receberam injeção de CFA na região das ATMs bilateralmente, e no $10^{\circ}$ dia experimental foi realizado o teste de avaliação da sensibilidade nociceptiva orofacial, pelo teste da formalina. 
Protocolo 2: Quantificação da expressão e da atividade das gelatinases MMP-2 e MMP-9 no núcleo trigeminal em ratos submetidos à inflamação persistente bilateral na $\underline{A T M}$

Grupo 1 ( $\mathrm{n}=8$, para cada período de sobrevida, MMP: SAL): ratos destes grupos receberam a injeção de solução salina $0,9 \%$ na região das ATMs e após o término do tempo de sobrevida, 1, 3, 7 ou 10 dias, os ratos foram submetidos à eutanásia para remoção dos gânglios trigeminais (conforme protocolo descrito item 5) para realização da zimografia e zimografia in situ, em grupos independentes de ratos.

Grupo 2 ( $\mathrm{n}=8$, para cada período de sobrevida, MMP: CFA): ratos destes grupos receberam a injeção de CFA na região das ATMs e após o término do tempo de sobrevida, 1, 3, 7 ou 10 dias, os ratos foram submetidos à eutanásia para remoção dos gânglios trigeminais (conforme protocolo descrito item 5) para realização da zimografia e zimografia in situ, em grupos independentes de ratos.

Protocolo 3: Avaliação do efeito da administração de um inibidor inespecífico das $\underline{\text { metaloproteinases sobre a sensibilidade mecânica e nociceptiva aguda em ratos portadores }}$ de inflamação persistente da ATM.

Grupo 1 ( $\mathrm{n}=8$, MEC: SAL+VEIC): ratos receberam injeção de solução salina 0,9 \% intraarticular bilateral nas ATMs, e em seguida foram submetidos à administração diária, via gavagem, de água destilada ( $1 \mathrm{~mL}$, veículo) durante 10 dias. No $10^{\circ}$ dia experimental foi avaliada a sensibilidade mecânica orofacial na região das ATMs, utilizando o anestesiomêtro modelo Von Frey.

Grupo 2 ( $n=8$, MEC: SAL+DOX): ratos receberam injeção de solução salina 0,9 \% intraarticular bilateral nas ATMs, e em seguida foram submetidos ao tratamento diário com um inibidor inespecífico de metaloproteinases, doxiciclina na dose de $30 \mathrm{mg} / \mathrm{Kg}$, durante 10 dias, via gavagem no volume de $1 \mathrm{~mL}$. No $10^{\circ}$ dia experimental foi avaliada 
a sensibilidade mecânica orofacial na região das ATMs, utilizando o anestesiomêtro modelo Von Frey.

Grupo 3 ( $\mathrm{n}=$ 8, MEC: CFA+VEIC): ratos receberam injeção de CFA intraarticular bilateral nas ATMs, e em seguida foram submetidos à administração diária, via gavagem, de água destilada ( $1 \mathrm{~mL}$, veículo) durante 10 dias. No $10^{\circ}$ dia experimental foi avaliada a sensibilidade mecânica orofacial na região das ATMs, utilizando o anestesiomêtro modelo Von Frey.

Grupo 4 ( $\mathrm{n}=8$, MEC: CFA+DOX): ratos receberam injeção de CFA intraarticular bilateral nas ATMs, e em seguida foram submetidos ao tratamento diário com um inibidor inespecífico de metaloproteinases, doxiciclina na dose de $30 \mathrm{mg} / \mathrm{Kg}$, durante 10 dias, via gavagem no volume de $1 \mathrm{~mL}$. No $10^{\circ}$ dia experimental foi avaliada a sensibilidade mecânica orofacial na região das ATMs, utilizando o anestesiomêtro modelo Von Frey.

Grupo 5 (n = 6, FORM: SAL+VEIC): ratos receberam injeção de solução salina 0,9 \% intraarticular bilateral nas ATMs, e em seguida foram submetidos à administração diária, via gavagem, de água destilada $\left(1 \mathrm{~mL}\right.$, veículo) durante 10 dias. No $10^{\circ}$ dia experimental foi avaliada a sensibilidade nociceptiva orofacial por meio do teste da formalina.

Grupo 6 ( $n=$ 6, FORM: SAL+DOX): ratos receberam injeção de solução salina 0,9 $\%$ intraarticular bilateral nas ATMs, e em seguida foram submetidos ao tratamento diário com um inibidor inespecífico de metaloproteinases, doxiciclina na dose de $30 \mathrm{mg}$ / $\mathrm{Kg}$, durante 10 dias, via gavagem no volume de $1 \mathrm{~mL}$. No $10^{\circ}$ dia experimental foi avaliada a sensibilidade nociceptiva orofacial por meio do teste da formalina.

Grupo 7 ( $n$ = 6, FORM: CFA+VEIC): ratos receberam injeção de CFA intraarticular bilateral nas ATMs, e em seguida foram submetidos à administração diária, via 
gavagem, de água destilada ( $1 \mathrm{~mL}$, veículo) durante 10 dias. No $10^{\circ}$ dia experimental foi avaliada a sensibilidade nociceptiva orofacial por meio do teste da formalina.

Grupo 8 (n = 6, FORM: CFA+DOX): ratos receberam injeção de CFA intraarticular bilateral nas ATMs, e em seguida foram submetidos ao tratamento diário com um inibidor inespecífico de metaloproteinases, doxiciclina na dose de $30 \mathrm{mg} / \mathrm{Kg}$, durante 10 dias, via gavagem no volume de $1 \mathrm{~mL}$. No $10^{\circ}$ dia experimental foi avaliada a sensibilidade nociceptiva orofacial por meio do teste da formalina.

\section{Eutanásia}

Após o término dos experimentos dos protocolos 1 e 3 os ratos foram submetidos à eutanásia por meio de sobredose anestésica com a utilização de uma associação de cetamina a $10 \%(225 \mathrm{mg} / \mathrm{Kg})$ e xilasina $4 \%(30 \mathrm{mg} / \mathrm{Kg})$ administrada intramuscular. Depois de confirmada a morte do animal (parada cárdio-respiratória por pelo menos 10 minutos e ausência de sensibilidade cutânea) os mesmos foram enviados para coleta biológica seletiva.

\section{Análise dos resultados}

Na avaliação da sensibilidade mecânica orofacial foi avaliada a média \pm erro padrão da média do limiar de retirada da cabeça, em gramas, antes e após a administração de CFA ou solução salina 0,9 \% nas ATMs. Na avaliação da sensibilidade nociceptiva orofacial foi considerada a média do tempo, em segundos, da emissão do comportamento de coçar a região orofacial ipsilateral à injeção de formalina $2 \% \pm$ erro padrão da média, em intervalos de 3 minutos. Para análise estatística foi utilizada a análise de variância (ANOVA) de uma via ou duas vias seguida pelo teste de Newman-Keuls, considerando para significância $P<0,05$. 
Para avaliação da expressão e da atividade gelatinolítica das MMPs foi realizada a quantificação por meio de unidades arbitrárias \pm erro padrão da média para cada MMP, ou seja, MMP-2 e MMP-9, em cada período de sobrevida avaliado. Foi utilizado para avaliação das imagens da zimografia e da zimografia in situ um sistema de imagens do laboratório da Profa. Dra. Raquel Fernanda Gerlach, e o programa de análise de imagens Image J. A análise estatística foi realizada por meio de análise de variância (ANOVA) de duas vias (variáveis independentes tempo e tratamento). Quando possível, foi realizado o teste post hoc de Newman-Keuls, considerando para significância $P<$ 0,05 . 


\section{Protocolo 1: Avaliação da sensibilidade mecânica e nociceptiva orofacial em ratos submetidos à administração de CFA intraarticular nas ATMs}

Os resultados do presente trabalho demonstram que a administração de CFA bilateralmente na região das ATMs promoveu tanto redução do limiar de estimulação mecânica orofacial (Figura 3) quanto aumentou à resposta nociceptiva no teste de formalina orofacial (Figura 4).

A avaliação dos resultados demonstra que no grupo controle (MEC: SAL) não foi demonstrada diferença de limiar mecânico 10 dias após a administração intraarticular de solução salina $0,9 \%(37,8 \pm 6,6 \mathrm{~g})$ quando comparado com o limiar no $10^{\circ}$ dia experimental (34,3 \pm 7,2 g, Figura 3). Em contraste, no grupo MEC: CFA a análise estatística evidenciou redução significativa $\left(\mathrm{F}_{1,11}=7,59, \mathrm{p}<0,05\right.$, ANOVA) entre o limiar de retirada da cabeça no período inicial $(38,03 \pm 3,26)$ quando comparado com o limiar $(\mathrm{P}<0,05$, Newman-Keuls $) 10$ dias após a administração do CFA intraarticular (23,6 44,09, Figura 3).

Considerando a sensibilidade nociceptiva, os dados mostraram que a injeção do CFA na ATM bilateralmente nos ratos promoveu aumento da resposta nociceptiva frente à administração de formalina $2 \%$ na região orofacial (Figura 4), durante todo o período experimental (fase 1 e fase 2).

Em particular, no grupo controle (FORM: SAL+SAL), não foi observado emissão de comportamento nociceptivo, sendo observado durante todo o período experimental apenas comportamento de auto-limpeza e exploração do ambiente. A média do tempo de coceira da região orofacial na fase 1 deste grupo foi de $1,1 \pm 0,7 \mathrm{~s}$, e na fase 2 , no período compreendido entre o $21^{\circ}$ e $24^{\circ}$ minuto, descrito como sendo o pico da $2^{\circ}$ fase (GRABOW \& DOUGHERTY, 2001) não foi observado comportamento de coceira (Figura 4). Considerando o grupo FORM: SAL+FORM os resultados demonstraram comportamento nociceptivo na fase $1(19,8 \pm 4$ s) seguido por um período silencioso, e o estabelecimento da fase 2 , com média de coceira orofacial de $42,8 \pm 7,4$ s no intervalo 
de 21 a 24 minutos de teste (Figura 4). Ainda, no grupo que recebeu a administração intraarticular de CFA (FORM: CFA+FORM) os resultados mostraram aumento do tempo de coceira (Figura 4) da região orofacial na fase $1(28,9 \pm 5,7$ s) e na fase 2 $(109,8 \pm 10 \mathrm{~s})$.

A aplicação da Two-way ANOVA evidenciou diferença significativa entre o tempo $\left(\mathrm{F}_{14,299}=12,354, \mathrm{P}<0,001\right)$ e o tratamento $\left(\mathrm{F}_{2,299}=214,824, \mathrm{P}<0,001\right)$ demonstrando interação tempo-tratamento $\left(\mathrm{F}_{28,299}=4,935, \mathrm{P}<0,001\right)$. O teste post hoc de Newman-Keuls mostrou que a média do tempo de coceira emitida pelos grupos FORM: SAL+FORM e FORM: CFA+FORM foi diferente significativamente $(\mathrm{P}<0,05)$ quando comparado com o tempo de coceira do grupo FORM: SAL+SAL durante todo o período experimental (Figura 4). Em adição, o tempo de comportamento nociceptivo do grupo FORM: CFA+FORM foi significativamente maior (Newman-Keuls, $\mathrm{P}<0,05$ ) quando comparado com o grupo FORM: SAL+FORM na fase 2 do teste de formalina (intervalos de 15 a 45 min, Figura 4). 


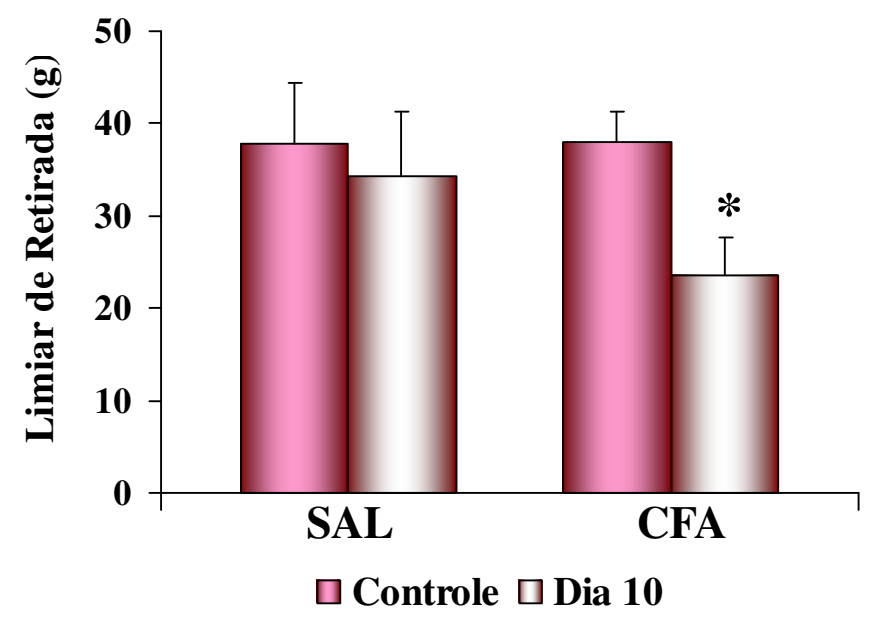

Figura 3: Limiar de Retirada (g) do reflexo de cabeça frente a um estímulo mecânico inócuo. SAL: Média do limiar de retirada (g) no período controle e 10 dias após a administração de solução salina 0,9 $\%$ bilateral na ATMs ( $\mathrm{n}=8$, MEC: SAL). CFA: Média do limiar de retirada (g) no período controle e 10 dias após a administração de Adjuvante Completo de Freund (CFA) bilateral na ATMs ( $n=8$, MEC: CFA). $\left({ }^{*}\right) \mathrm{P}<0,05$, teste de Newman-Keuls comparado com período controle.

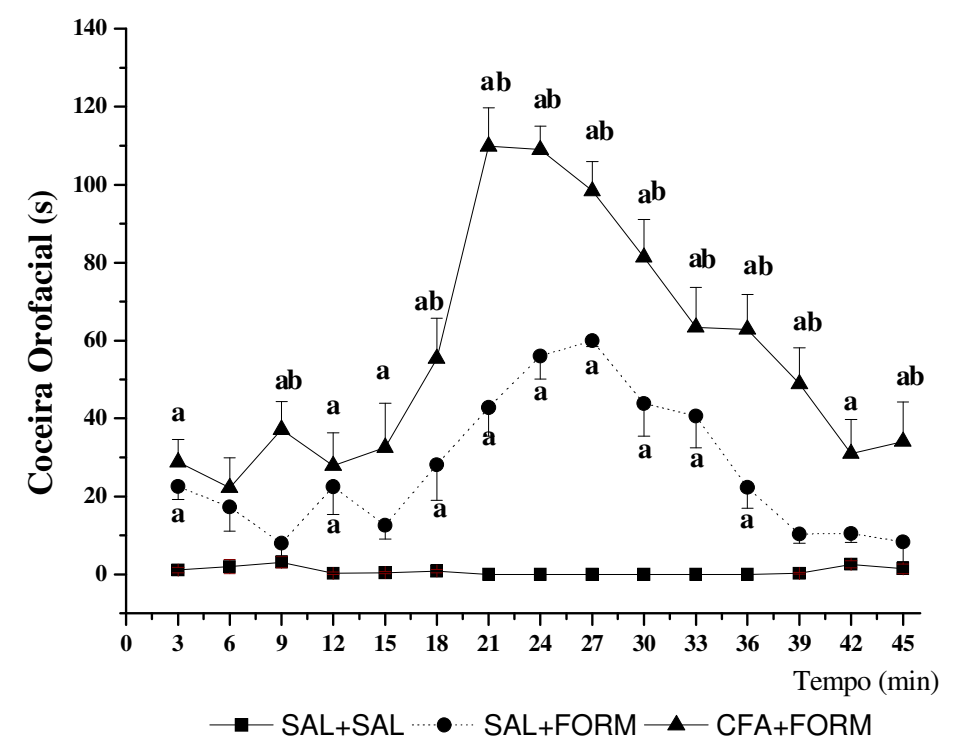

Figura 4. Avaliação do comportamento nociceptivo no teste de formalina orofacial. SAL+SAL média \pm EPM do tempo de coceira orofacial (s) do grupo submetido à administração de solução salina $0,9 \%$ intraarticular e 10 dias após solução salina $0,9 \%$ na região das vibrissas $(n=7)$, CFA+FORM média \pm EPM do tempo de coceira orofacial (s) do grupo que recebeu administração de solução salina $0,9 \%$ intraarticular e 10 dias após formalina 2\% na região das vibrissas $(n=6)$, e CFA+FORM média \pm EPM do tempo de coceira orofacial (s) onde se administrou Adjuvante Completo de Freund (CFA) na região da articulação temporomandibular bilateral e 10 dias após formalina $2 \%$ na região das vibrissas $(n=7)$. (a) $\mathrm{P}<0,05$ teste Newman-Keuls, quando comparado com o grupo SAL+SAL, (b) $\mathrm{P}<0,05$ teste de Newman-Keuls, quando comparado com SAL+FORM. EPM: erro padrão da média. 


\section{Protocolo 2: Quantificação da expressão e da atividade das gelatinases MMP-2 e} MMP-9 no núcleo trigeminal em ratos submetidos à inflamação persistente

\section{bilateral na ATM}

Os resultados mostraram aumento da expressão das MMPs em gânglio trigeminal, em particular da MMP-2 (75 kDa, $72 \mathrm{kDa}$ e $64 \mathrm{kDa})$ e MMP-9, nos grupos experimentais que receberam administração intraarticular de CFA (Figuras 5, 6 e 7). Ainda, a zimografia in situ mostra aumento significativo da atividade gelatinolítica das MMPs em gânglios trigeminais nos grupos tratados com CFA bilateralmente na região das ATMs nos distintos tempos de sobrevida estudados, 1, 3, 7 e 10 dias (Figuras 8 e 9).

Considerando a MMP-9, os resultados evidenciam que sua expressão no gânglio trigeminal está aumentada 1 e 3 dias após o tratamento com CFA intraarticular. A aplicação da Two-Way ANOVA revelou diferença significativa do tempo $\left(\mathrm{F}_{3,54}=\right.$ 15,618, $\mathrm{P}<0,001)$, do tratamento $\left(\mathrm{F}_{1,54}=18,961, \mathrm{P}<0,001\right)$, e interação tempo e tratamento $\left(\mathrm{F}_{3,54}=3,715, \mathrm{P}<0,01\right)$. O teste post hoc de Neuwman-Keuls mostrou diferença significativa $(\mathrm{P}<0,05)$ da expressão da MMP-9 entre os grupos MMP: CFA quando comparados com os grupos MMP: SAL no $1^{\circ}$ e $3^{\circ}$ dia após o início do processo inflamatório (Figura 6).

Os dados da quantificação das MMPs-2 (75 kDa, 72 kDa e 64 kDa) mostraram aumento significativo de sua expressão no gânglio trigeminal, principalmente no $3^{\circ}, 7^{\circ} \mathrm{e}$ $10^{\circ}$ dia após a administração do CFA intraarticular (Figura 7). A análise individual da MMP-2 $75 \mathrm{kDa}$ revelou diferença significativa no tempo $\left(\mathrm{F}_{3,62}=88,870, \mathrm{P}<0,001\right.$, Two-Way ANOVA), do tratamento ( $\mathrm{F}_{1,62}=48,570, \mathrm{P}<0,001$, Two-Way ANOVA), e interação tempo e tratamento $\left(\mathrm{F}_{3,62}=6,259, \mathrm{P}<0,001\right.$, Two-Way ANOVA). O teste post hoc de Neuwman-Keuls mostrou diferença significativa $(\mathrm{P}<0,05)$ da expressão da MMP-2 75 kDa entre os grupos MMP: CFA quando comparados com os grupos MMP: SAL no $3^{\circ}, 7^{\circ}$ e $10^{\circ}$ dia após o início do processo inflamatório (Figura 7). Com relação à 
MMP-2 72 kDa (Figura 7), a aplicação da Two-way ANOVA evidencia diferença significativa do tempo $\left(\mathrm{F}_{3,67}=16,312, \mathrm{P}<0,001\right)$, do tratamento $\left(\mathrm{F}_{1,67}=40,352, \mathrm{P}<\right.$ 0,001), e entretanto não houve interação tempo e tratamento $\left(\mathrm{F}_{3,67}=2,341, \mathrm{P}=0,082\right)$. Ainda, com relação à MMP-2 $64 \mathrm{kDa}$, a análise estatística demonstrou diferença significativa no tempo $\left(\mathrm{F}_{3,67}=7,003, \mathrm{P}<0,001\right.$, Two-Way ANOVA), do tratamento $\left(F_{1,67}=94,717, P<0,001\right.$, Two-Way ANOVA $)$, e interação tempo e tratamento $\left(F_{3,67}=\right.$ 3,409, P < 0,05, Two-Way ANOVA) evidenciando aumento significativo da expressão desta MMP no gânglio trigeminal. O teste post hoc de Newman Keuls revelou diferença significativa $(\mathrm{P}<0,05)$ entre os grupos MMP: CFA quando comparados com os grupos MMP: SAL em todos os tempos experimentais analisados (1, 3, 7 e 10 dias, Figura 7).

Em adição, os resultados da análise da atividade gelatinolítica das MMPs em gânglio trigeminal mostraram aumento significativo considerando o tempo $\left(\mathrm{F}_{3,63}=\right.$ $4,124, \mathrm{P}=0,01$, Two-Way ANOVA), o tratamento $\left(\mathrm{F}_{1,63}=499,33, \mathrm{P}<0,001\right.$, TwoWay ANOVA), e com interação tempo e tratamento $\left(\mathrm{F}_{3,63}=4,123, \mathrm{P}=0,01\right.$, Two-Way ANOVA). Na aplicação do teste de Newman-Keuls foi evidenciada diferença significativa entre os grupos MMP: CFA e MMP: SAL em todos os períodos de tempo analisados (1, 3, 7 e 10 dias, Figura 9). Na figura 8 podem ser observadas fotomicrografias de cortes transversais dos gânglios trigeminais de ratos representativos dos diferentes grupos experimentais realizados neste trabalho, evidenciando a atividade enzimática das MMPs, em particular MMP-2 e MMP-9, através da fluorescência verde. 

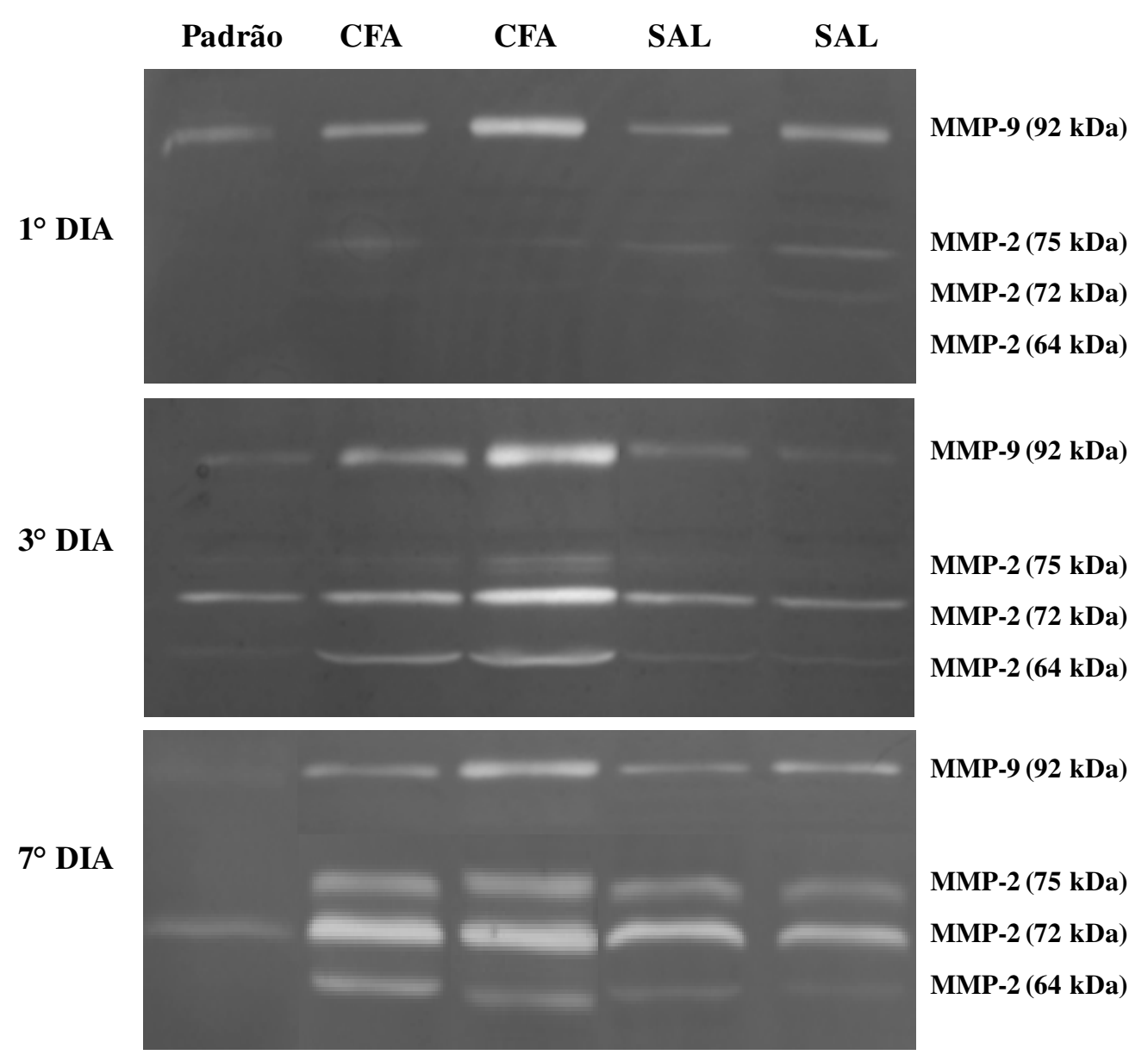

MMP-9 (92 kDa)

MMP-2 (75 kDa)

MMP-2 (72 kDa)

MMP-2 (64 kDa)

$10^{\circ}$ DIA

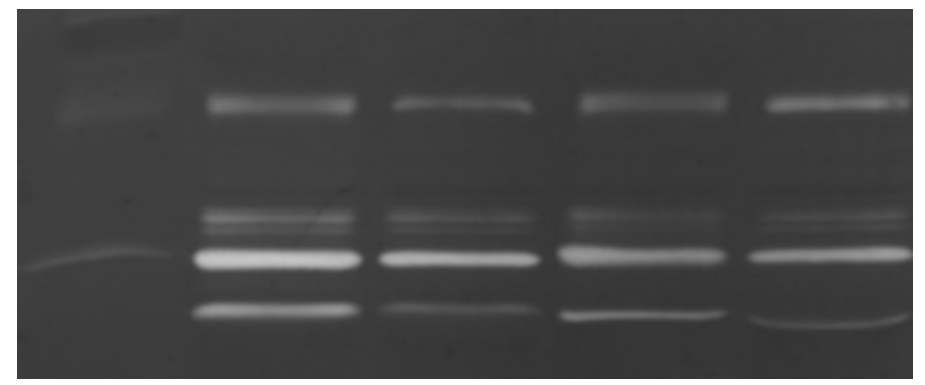

MMP-9 (92 kDa)

MMP-2 (75 kDa)

MMP-2 (72 kDa)

MMP-2 (64 kDa)

Figura 5: Fotografia de zimograma representativo de gânglios trigeminais de ratos de diferentes grupos experimentais, 1, 3, 7 ou 10 dias após a administração intraarticular bilateral na ATM de solução salina 0,9 \% (SAL) ou Adjuvante Completo de Freund (CFA). A figura apresenta a expressão da metaloproteinases MMP-2 (75, 72 e 64 kDa) e MMP-9 (92 kDa) em suas distintas localizações no gel de zimografia. 


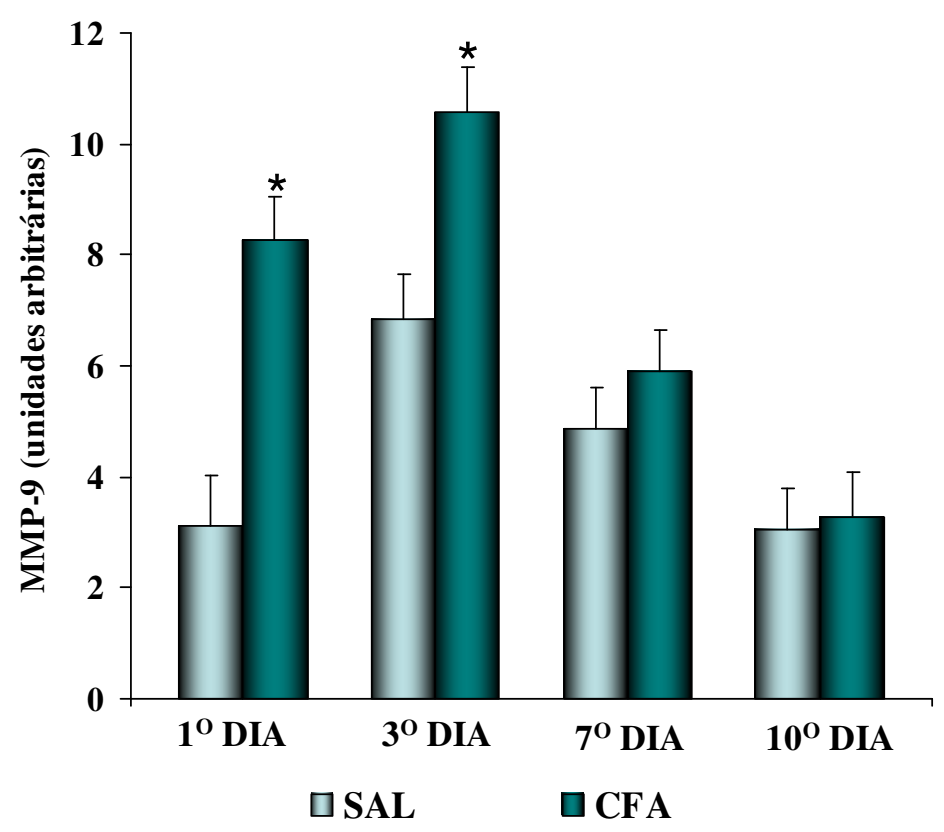

Figura 6: Avaliação quantitativa da expressão de gelatinases MMP-9 (unidades arbitrárias) em gânglios trigeminais em diferentes períodos experimentais. Média \pm EPM da expressão de MMP-9 nos grupos submetidos à administração de solução salina 0,9 \% (SAL) ou Adjuvante Completo de Freund (CFA) bilateral na ATM com tempo de sobrevida de 1, 3, 7 ou 10 dias. (*) $\mathrm{P}<0,05$, Newman-Keuls, quando comparado com os valores do respectivo grupo SAL EPM: erro padrão da média. 


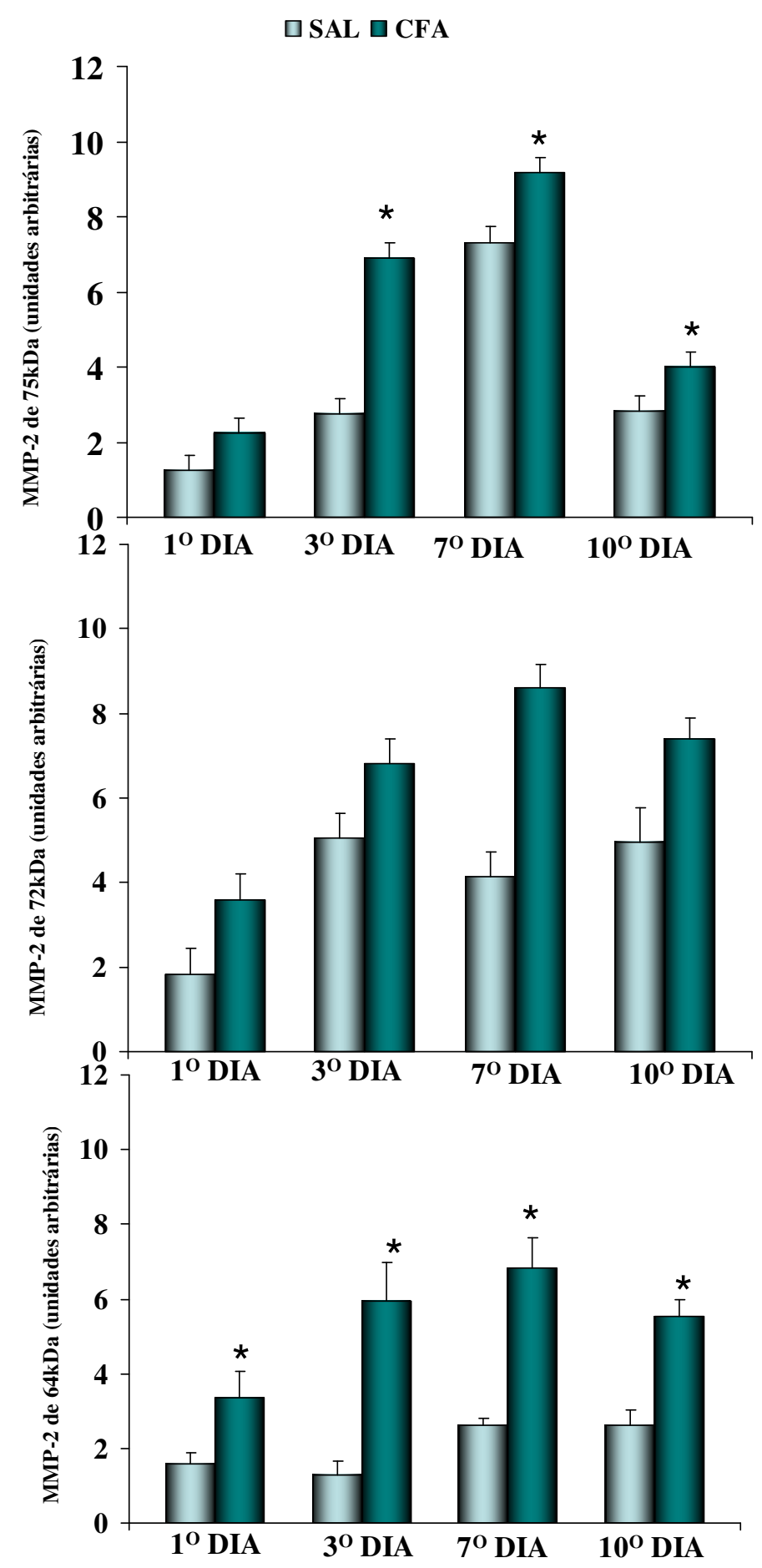

Figura 7: Avaliação quantitativa da expressão de gelatinases MMP-2 (unidades arbitrárias) em gânglios trigeminais em diferentes períodos experimentais. Média \pm EPM da expressão de MMP-2 (75 $\mathrm{kDa}, 72 \mathrm{kDa}$ e $64 \mathrm{kDa}$ ) nos grupos submetidos à administração de solução salina 0,9 \%(SAL) Adjuvante Completo de Freund (CFA) bilateral na ATM (SAL) com tempo de sobrevida de 1, 3, 7 ou 10 dias. (*) $\mathrm{P}<0,05$, Newman-Keuls, quando comparado com os valores do respectivo grupo SAL EPM: erro padrão da média. 


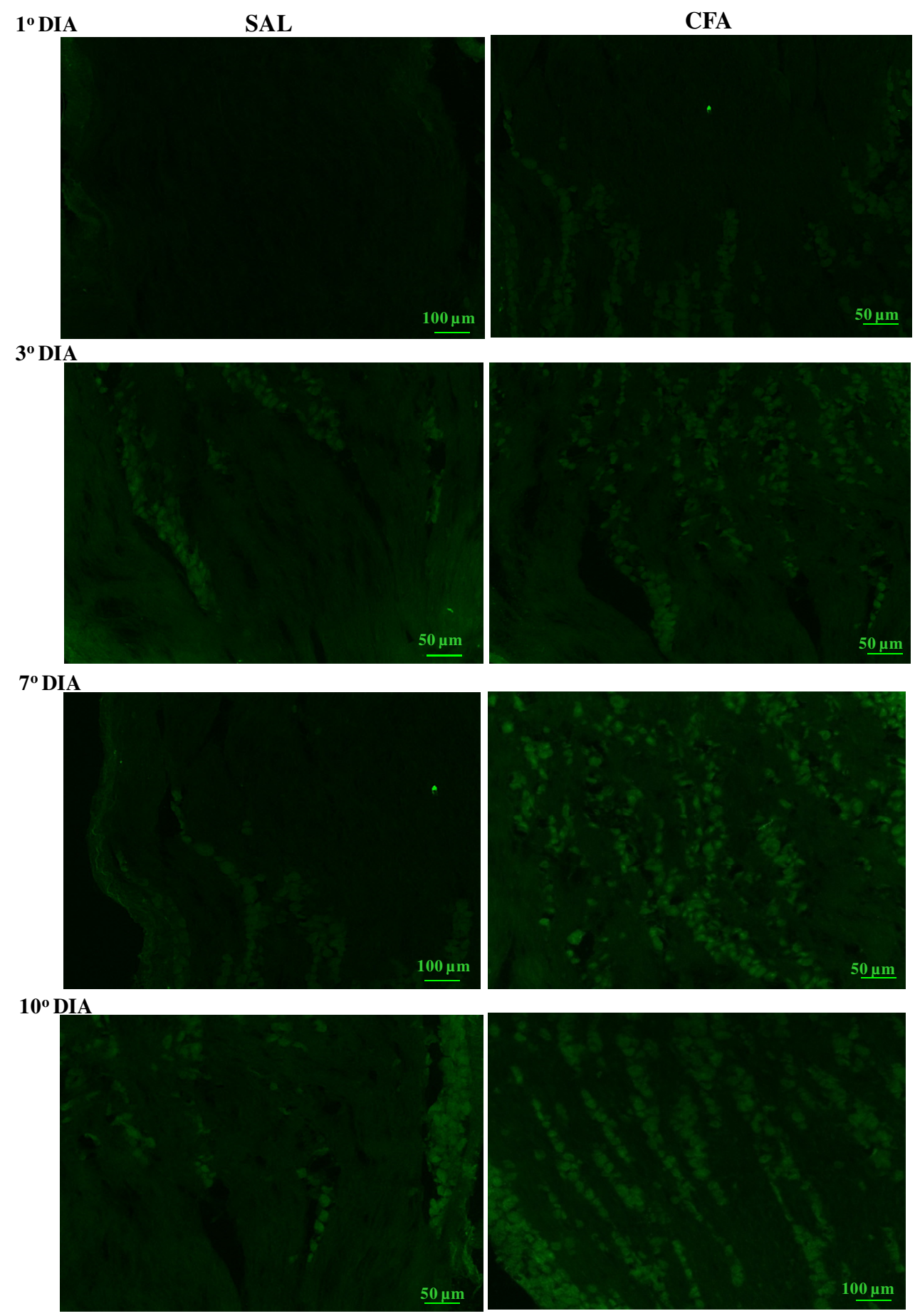

Figura 8: Fotomicrografias representativas de cortes longitudinais $(14 \mu \mathrm{m})$ do tronco encefálico de ratos, região do gânglio trigeminal, evidenciando a atividade gelatinolítica das MMPs 1 dia ou 3, 7 e 10 dias após a administração de solução salina 0,9 \% (SAL) ou Adjuvante Completo de Freund (CFA) bilateralmente na articulação temporomandibular (Fluorescência verde, aumento 20x). 


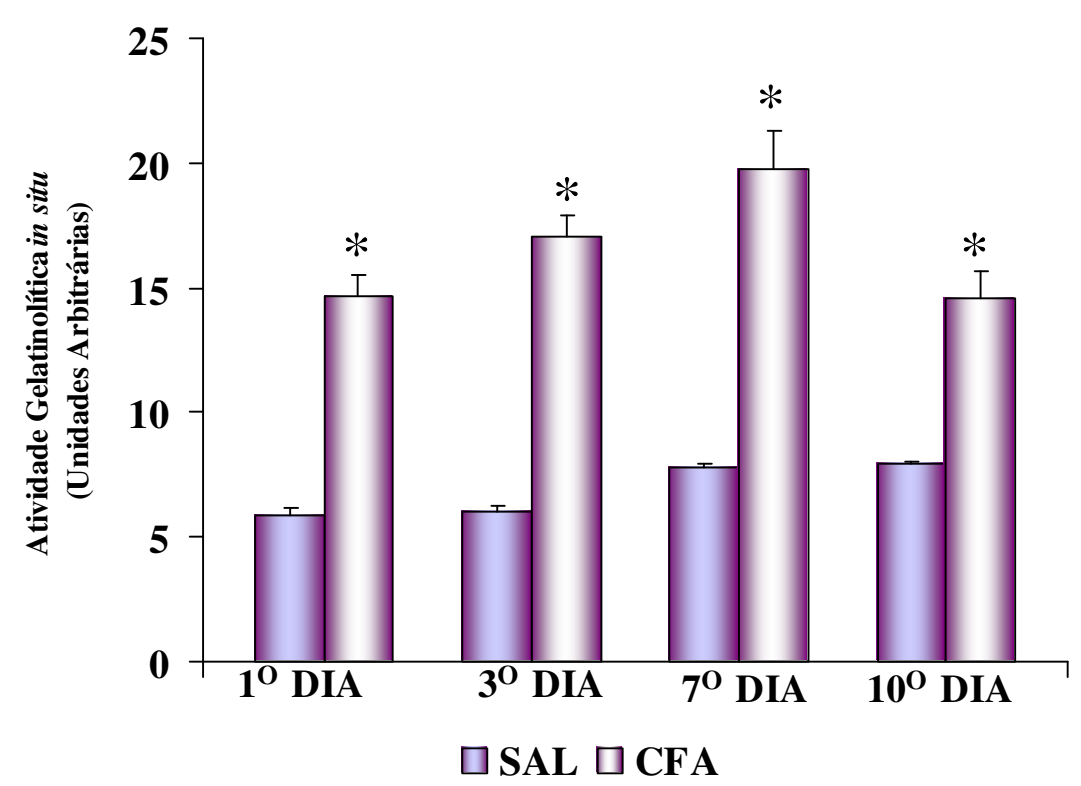

Figura 9: Quantificação da porcentagem de área da superfície do gânglio trigeminal coberta por fluorescência verde, caracterizando a atividade gelatinolítica das MMPs. Média \pm EPM da atividade gelatinolítica (unidade arbitrária) após 1, 3, 7 ou 10 dias da administração de solução salina 0,9\% (SAL) ou Adjuvante Completo de Freund (CFA) intraarticular bilateral na ATM de ratos. (*) $\mathrm{P}<0,05$, Newman-Keuls, quando comparado com os valores de seus respectivos valores do grupo controle (SAL). EPM: erro padrão da média. ( $n=8$ para cada grupo experimental). 


\section{Protocolo 3: Avaliação do efeito da administração de um inibidor inespecífico das} metaloproteinases sobre a sensibilidade mecânica e nociceptiva aguda em ratos portadores de inflamação persistente da ATM

Os resultados do presente trabalho mostraram que o tratamento (via gavagem) durante 10 dias com doxiciclina (inibidor inespecífico de MMPs), iniciando no dia da administração intraarticular bilateral na ATM de CFA, bloqueou a redução do limiar de retirada do reflexo de cabeça frente a um estímulo mecânico inócuo na região orofacial (Figura 11). Em adição, o uso da doxiciclina reduziu o comportamento nociceptivo da segunda fase do teste da formalina orofacial (Figura 12B).

A análise estatística realizada mostrou que nos grupos que receberam administração de solução salina 0,9 \% (SAL+VEIC, SAL+DOX) intraarticular bilateral na ATM não há diferença significativa $\left(\mathrm{F}_{1,15}=0,060, \mathrm{P}>0,05, \mathrm{~F}_{1,15}=0,592, \mathrm{P}>0,05\right.$, One-way ANOVA, para os grupos MEC: SAL+VEIC e MEC: SAL+DOX respectivamente) entre o limiar de retirada inicial e 10 dias após o tratamento diário com doxiciclina ou veículo (Figura 10). Entretanto, no grupo onde se administrou CFA intraarticular bilateralmente na ATM e que recebeu o tratamento com doxiciclina por 10 dias, a redução do limiar de retirada (g) de cabeça iniciado por um estímulo mecânico inócuo (grupo MEC: CFA+DOX) foi bloqueada (Figura 11). Neste grupo, a análise estatística revelou que não há diferença significativa $\left(\mathrm{F}_{1,15}=0,983, \mathrm{P}>0,05\right.$ One-way ANOVA) quando comparado a média do limiar de retirada do período inicial com a média do limiar de retirada 10 dias após o início dos experimentos. Em adição, no grupo MEC: CFA+VEIC observou-se redução significativa $\left(\mathrm{F}_{1,15}=17,308, \mathrm{P}<0,001\right.$, Oneway ANOVA) do limiar de retirada 10 dias após a administração de CFA $(\mathrm{P}<0,05$, Newman Keuls) comparado com o limiar de retirada do período inicial (Figura 11).

Em relação à sensibilidade nociceptiva, os resultados demonstraram que o tratamento com doxiciclina durante 10 dias foi capaz de promover redução do 
comportamento nociceptivo na segunda fase do teste da formalina orofacial induzido pela administração intraarticular de CFA bilateralmente na ATM de ratos (Figura 12). A aplicação da Two-way ANOVA evidenciou diferença significativa entre o tempo $\left(\mathrm{F}_{14,359}\right.$ $=9,859, \mathrm{P}<0.001)$ e o tratamento $\left(\mathrm{F}_{3,359}=38,907, \mathrm{P}<0.001\right)$ revelando interação tempo-tratamento $\left(\mathrm{F}_{42,359}=2,191, \mathrm{P}<0.001\right)$. O teste post hoc de Newman-Keuls mostrou que a média do tempo de coceira emitida pelo grupo FORM: CFA+VEIC, foi significativamente diferente $(\mathrm{P}<0,05)$ quando comparado com o tempo de coceira do grupo FORM: CFA+DOX na segunda fase do teste de formalina orofacial, em particular nos intervalos de 6-9 min, 15-18 min, 24-27 min, 27-30 min , 33-36 min e 4245 min (Figura 12B). Em adição, o tempo de comportamento nociceptivo do grupo FORM: CFA+VEIC foi estatisticamente maior (Newman-Keuls, $\mathrm{P}<0,05)$ quando comparado com o grupo FORM: SAL+VEIC e FORM: SAL+DOX na fase 2 do teste de formalina (intervalos de 15-18 $\mathrm{min}, 21-24 \mathrm{~min}, 24-27 \mathrm{~min}, 27-30 \mathrm{~min}, 33-36 \mathrm{~min}, 36-39$ e 42-45 min, Figura 12).

Nos grupos que receberam administração intraarticular de solução salina $0,9 \%$ (SAL) e foram submetidos ao tratamento com doxiciclina (DOX) ou seu veículo por 10 dias (VEIC) a injeção subcutânea de formalina 2\% na região das vibrissas promoveu comportamento nociceptivo típico do teste de formalina orofacial, amplamente descrito na literatura. Na Figura 12A podem ser evidenciadas as duas fases nociceptivas deste teste, sendo a fase 1 no intervalo de 0 a 3 min, e a fase 2 iniciando no intervalo de 15 minutos de teste. O pico do comportamento nociceptivo na segunda fase é observado no intervalo de 24 a 27 minutos. 


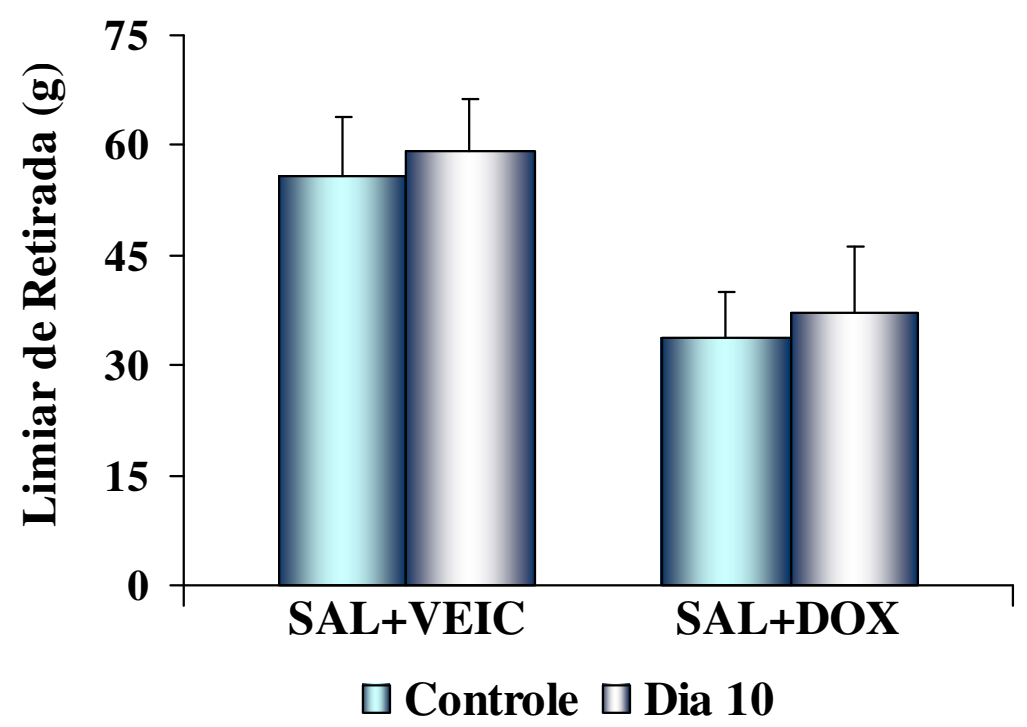

Figura 10: Média do limiar de retirada da cabeça $(\mathrm{g}) \pm$ EPM frente a um estímulo mecânico inócuo no período inicial (Controle) e 10 dias após a administração de solução salina $0,9 \%$ (SAL) intraarticular e do tratamento diário com doxiciclina (DOX, $30 \mathrm{mg} / \mathrm{Kg}, \mathrm{n}=8$ ) ou seu veículo (VEIC, $\mathrm{n}=8$ ).

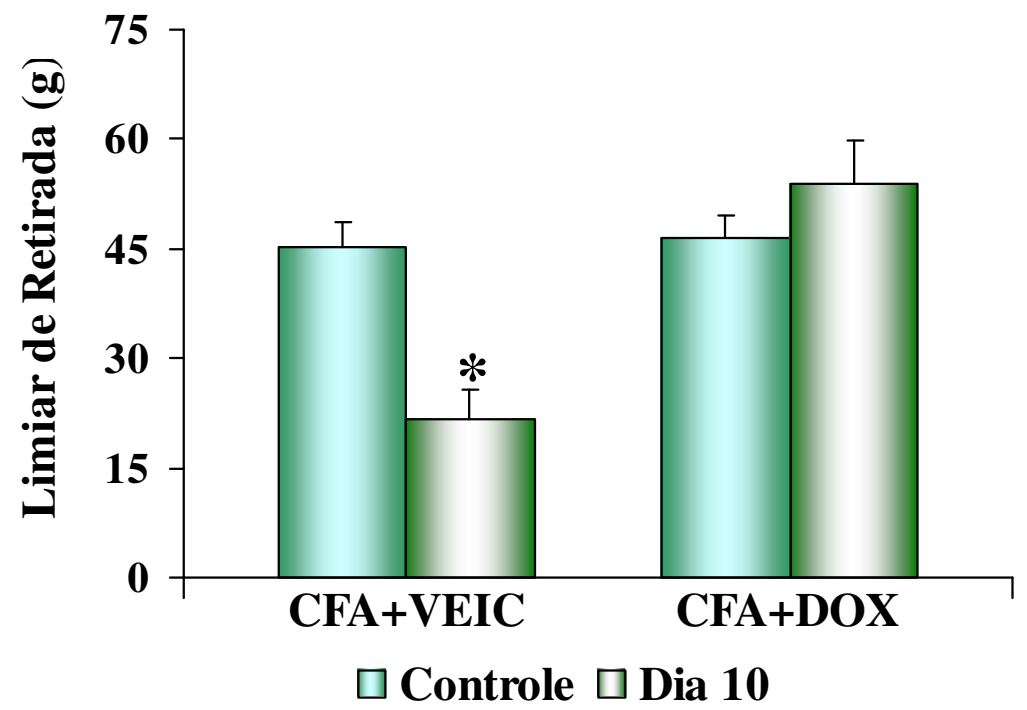

Figura 11: Média do limiar de retirada da cabeça $(\mathrm{g}) \pm$ EPM frente a um estímulo mecânico inócuo no período inicial (Controle) e 10 dias após a administração de Adjuvante Completo de Freund (CFA) intraarticular e do tratamento diário com doxiciclina (DOX, $30 \mathrm{mg} / \mathrm{Kg}, \mathrm{n}=8$ ) ou seu veículo (VEIC, $\mathrm{n}=8$ ). 


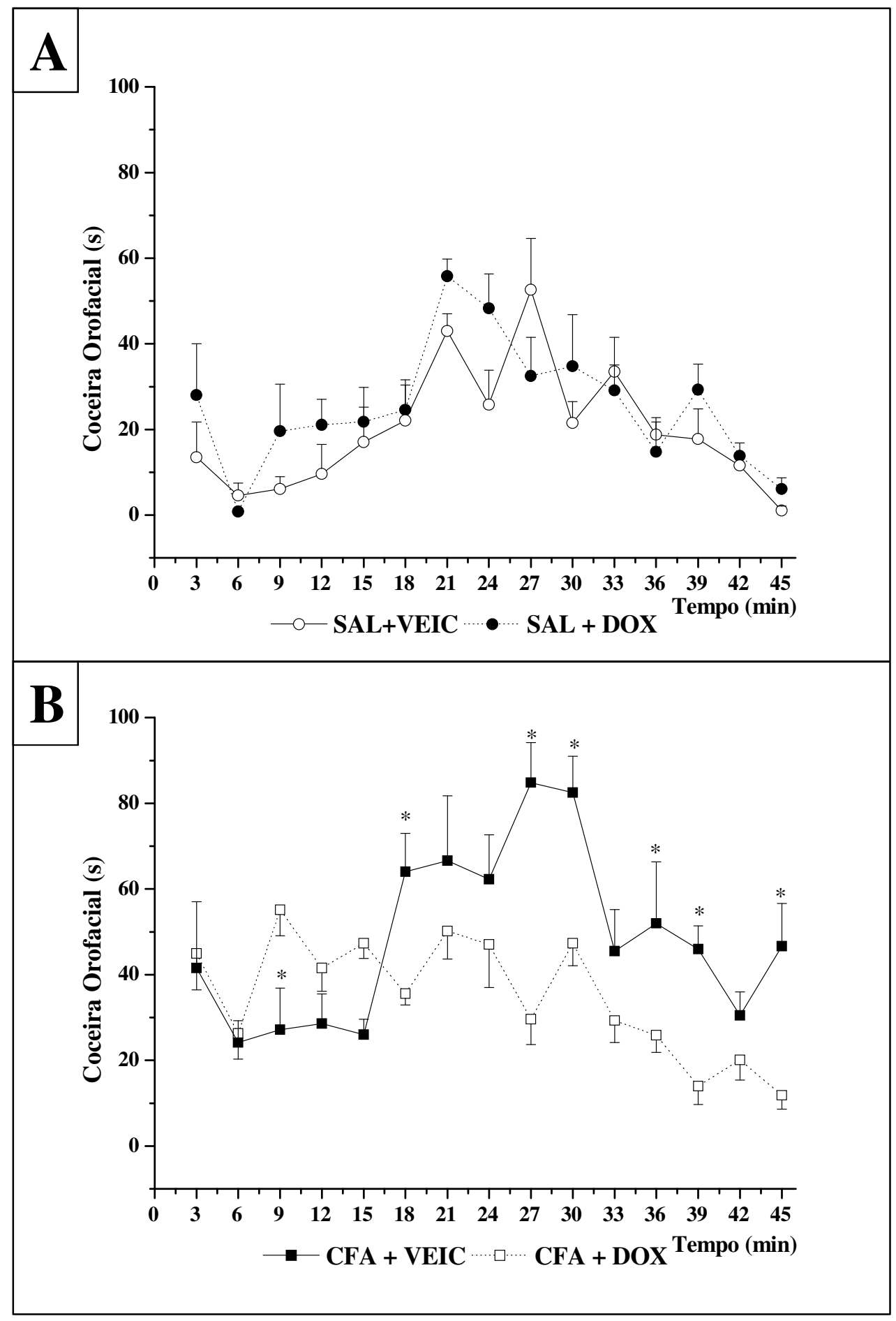

Figura 12: Avaliação da sensibilidade nociceptiva. A: Média \pm EPM da coceira orofacial (s) no teste de formalina (2\%) em grupo que recebeu solução salina 0,9 \% (SAL) na região das ATMs e foi submetido ao tratamento diário por 10 dias com doxiciclina (DOX, $\mathrm{n}=6$ ) ou seu veículo (VEIC, $\mathrm{n}=6$ ). B: Média \pm EPM da coceira orofacial (s) no teste da formalina (2\%) em grupo que recebeu Adjuvante Completo de Freund (CFA) na região das ATMs e foi submetido ao tratamento diário por 10 dias com doxiciclina (DOX, $\mathrm{n}=6$ ) ou seu veículo (VEIC, $\mathrm{n}=6$ ). (*) P $<0,05$, Newman Keuls quando comparado com grupo CFA+DOX. EPM: erro padrão da média. 
Desordens na articulação temporomandibular frequentemente envolvem o componente inflamatório (GOULET e cols., 1995). No presente estudo, a administração de CFA bilateralmente na região das ATMs reduziu o limiar de retirada de cabeça frente a um estímulo mecânico inócuo, bem como potencializou a emissão de comportamentos nociceptivos (coceira), no teste de formalina orofacial, em particular na fase tardia, 10 dias após o tratamento. Estes resultados sugerem que a administração de CFA intraarticular nas ATMs promoveu inflamação persistente, a qual foi responsável pela alteração da sensibilidade mecânica e nociceptiva orofacial, evidenciando a alodinia mecânica e a hiperalgesia observadas nos resultados obtidos neste estudo. De fato, as disfunções temporomandibulares incluem uma variedade de sintomas tais como a dor persistente na região orofacial e a severidade desta dor pode ser conseqüência de alterações neuroplásticas no SNC após lesões em tecidos periféricos (DUBNER, 1991). Assim, este tipo de lesão induz a um estado de hiperexcitabilidade no sistema trigeminal, o que pode acarretar na dor persistente.

Estudos demonstraram a capacidade do Adjuvante Completo de Freund em promover inflamação persistente na região da ATM. Além disso, ratos que receberam administração de CFA intraarticular (ATM) apresentaram aumento da emissão do comportamento de auto-limpeza e atenção com a superfície do corpo, e alteração do padrão de sono (SCHUTZ e cols., 2003). Estas alterações comportamentais foram reduzidas após o tratamento com indometacina, um antiinflamatório não-esterioidal. Estes resultados suportam a hipótese de que a administração de CFA intraarticular na região da ATM é capaz de promover alterações comportamentais, associadas ao processo inflamatório persistente. De fato, estudos neuroquímicos demonstraram que a inflamação na ATM promove a produção de substâncias pró-inflamatórias, incluindo taquicininas como a substância P e peptídeos como o CGRP (CARLESSON e cols., 1997). Além desses mediadores, pacientes com DTM apresentam altos níveis da 
citocina IL-1 $\beta$ no fluido sinovial (HARPER e cols., 2000). Trabalho de HARPER e cols. (2001) demonstrou, através da administração de CFA na ATM de ratos, aumento dose-dependente da concentração de IL-1 $\beta$ no tecido retrodiscal, atingindo seu máximo na dose de $50 \mu \mathrm{g}$ de CFA. Desta forma, considerando que a inflamação é acompanhada de alteração do limiar de sensibilidade nociceptiva, bem como alteração da sensibilidade mecânica, pode-se sugerir que a alodinia mecânica e a hiperalgesia orofacial observadas em nossos resultados são devido à instalação do processo inflamatório persistente decorrente da administração de CFA intraarticular nas ATMs.

Outros estudos corroboram nossos achados mostrando que ocorre sensibilização das vias nociceptivas trigeminais decorrente de injúrias de nervo periférico ou do aumento da atividade dos nociceptores (por exemplo, devido à ativação continuada observada em processos inflamatórios) contribuindo para a hiperalgesia e para amplificação da dor persistente. Ainda, intensa excitabilidade neuronal, avaliada pelo aumento da expressão da proteína FOS, em particular no complexo sensorial trigeminal, é observada após estimulação nociceptiva de tecidos profundos (DUBNER e REN, 2004), tal como a ATM.

A utilização do Adjuvante Completo de Freund (CFA) como agente indutor de inflamação e hiperalgesia iniciou-se em modelos voltados à sensibilização periférica, sendo administrado nos membros posteriores de ratos (STEIN e cols., 1988). Anos mais tarde, seguindo o mesmo princípio, ZHOU e cols. (1999) adaptaram este modelo, para a região da ATM, sendo este atualmente utilizado em ampla escala como um modelo de inflamação temporomandibular (IMBE e cols., 1999), e com similaridade com situações clínicas de pacientes portadores de DTM. De fato, estudos demonstraram que a administração de CFA na ATM promoveu hiperalgesia persistente com intensa hiperexcitabilidade de neurônios do núcleo espinal do trigêmeo (IWATA e cols., 1999) 
e do núcleo paratrigeminal (YAMAZAKI e cols., 2008). Em adição, ocorre expansão dos campos receptivos de neurônios nociceptivos trigeminais (IWATA e cols., 1999).

Em particular, é possível que o desenvolvimento da hiperexcitabilidade neuronal e da dor persistente envolvam a ativação de receptores NMDA (REN e cols., 1996). Corroborando esta hipótese, Guo e cols. (2002) demonstraram aumento dos receptores NMDA no corno dorsal da medula espinhal, após administração intraplantar de CFA em ratos. Em adição, Ro (2003) mostra a participação de receptores NMDA na nocicepção orofacial e na formação de edema decorrente da inflamação causada pela administração de óleo de mostarda na região massetérica de ratos.

Considerando a análise da expressão de MMPs no gânglio trigeminal, os resultados do presente trabalho demonstraram que o desenvolvimento da inflamação persistente da região da ATM promoveu alteração da expressão das MMPs, em particular, da MMP-2 e da MMP-9. Ainda, observa-se que há aumento diferenciado destas gelatinases, de forma tempo-dependente. No início da instalação do processo inflamatório há aumento da expressão da MMP-9, enquanto que a resposta tardia é mantida acompanhada de maior expressão da MMP-2. Dando suporte a estes achados, o envolvimento das MMPs em processos inflamatórios da região da ATM é reportado em diversos estudos. Dentro deste contexto, a expressão das MMPs no líquido sinovial da ATM é aceita como um potencial marcador bioquímico da osteoartrite avançada na ATM (SRINIVAS e cols., 2001; TANAKA e cols., 2001). De fato, aumento significativo das citocinas inflamatórias IL-1 $\beta$ e IL-6, bem como das formas ativas das MMPs 2 e 9 foi observado no líquido sinovial da ATM durante o processo inflamatório local (KUBOTA e cols., 1998). Além da presença das MMPs do tipo gelatinase (MMP2 e MMP-9), há aumento da expressão de MMP do tipo colagenases, MMP-1, MMP-8 e MMP-13, no líquido sinovial da ATM acompanhando a inflamação da ATM e reforçando a importância da cascata de MMPs na patogênese da DTM (SRINIVAS e 
cols., 2001). É possível que o aumento da produção de MMP-2 e MMP-9 origine-se de células do revestimento sinovial, dos fibroblastos e dos condrócitos (YOSHIDA e cols., 2006). Entretanto, evidências demonstram que a MMP-9 é produzida em grande quantidade por células inflamatórias, enquanto que a MMP-2, tem origem dos fibroblastos. Corroborando com nossos resultados, estes achados sugerem que MMP-9 está associada com condições inflamatórias agudas da articulação, enquanto que a MMP-2 está mais relacionada com aspectos mais tardios da resposta inflamatória, tal qual a degranulação dos neutrófilos (GAUDIN e cols., 1997; COUGHLAN e cols., 1998).

Dentro deste contexto, há evidências demonstrando o envolvimento da MMP-9 na hiperalgesia promovida pela IL-17 observada em um modelo de artrite reumatóide induzida pelo antígeno mBSA em camundongos. Neste trabalho, foi mostrado que a injeção de IL-17 intraarticular promoveu aumento da expressão de MMP-9 em tecido sinovial, enquanto que o pré-tratamento com doxiciclina (30 mg/ $\mathrm{kg})$, um inibidor nãoespecífico das MMPs, promoveu diminuição do efeito pró-nociceptivo do mBSA e da hipernocicepção provocada pela IL-17 (PINTO e cols., 2010). Assim, é possível que as MMPs estejam envolvidas na degradação de matriz extracelular que ocorre em processos inflamatórios, bem como, atue como estímulo para produção e atuação de mediadores inflamatórios, tais como da IL-17 (JOVANOVIC e cols., 1998).

Considerando o sistema nervoso, vários achados demonstram que as MMPs são expressas em diversas regiões do cérebro, especialmente em condições patológicas, nas quais as células gliais, bem como, células inflamatórias formam os principais substratos para a atividade destas proteases. Desta forma, foi observada, em modelo de isquemia cerebral em ratos e em camundongos, a expressão e a ativação da MMP-2 foram localizadas em neurônios, células gliais e no endotélio; enquanto que a MMP-9 foi encontrada em níveis elevados em neurônios e células gliais, bem como em feixes de 
fibras mielinizadas. Ainda, identificou-se expressão aumentada de MMP-3 em neurônios (YONG e cols., 2001). Especificamente em gânglios neurais, a MMP-2 está constitutivamente expressas no gânglio cervical superior de roedores (PAGGI, e cols., 2006). Além disso, Leone e cols. (2005) demonstraram, através da zimografia in situ, que cinco dias após axotomia de neurônios localizados no gânglio cervical superior, ocorre aumento da atividade enzimática da MMP-2, principalmente ao redor dos neurônios ganglionares, e as sinapses intraganglionares são significativamente alteradas.

Corroborando com os achados do presente trabalho, estudo de Kawasaki e cols. (2008) demonstrou que as gelatinases MMP-2 e MMP-9 exercem papéis diferentes durante o quadro de dor neuropática. No primeiro estágio da dor, observou-se a presença de maior quantidade de MMP-9 no gânglio da raiz dorsal, sugerindo rápida e transitória participação desta metaloproteinase no desenvolvimento da dor neuropática. Em contraste, o aumento da expressão da MMP-2 foi mais tardio, constituindo uma fase de manutenção da dor neuropática. Os mecanismos pelos quais estas enzimas contribuem para a gênese da dor neuropática parecem envolver a estimulação da produção da citocina pró-inflamatória IL-1 $\beta$, que também desempenha papel importante na gênese da dor neuropática.

Ainda sobre a correlação entre as MMPs o desenvolvimento da dor e o sistema nervoso, foi demonstrado que as MMPs promovem dano na bainha de mielina através da degradação da proteína básica mielínica em um modelo de neuropatia periférica (KOBAYASHI e cols., 2008). Neste estudo, a inibição das MMPs atenuou o início e a manutenção da alodinia mecânica. Outros estudos têm estabelecido a importância das MMPs no comportamento nociceptivo. Dentro deste contexto, foi demonstrado que ratos knockout para um gene responsável pelas MMPs não desenvolveram alodinia mecânica após a ligadura parcial do nervo ciático (KOMORI e cols, 2004). Ainda, ratos knockout para MMP-9 mostraram redução do índice de dor espontânea após 
esmagamento do nervo ciático (CHATTOPADHYAY e cols., 2007). Estudos mostraram que em ratos pré-tratados com um inibidor de MMPs ocorreu diminuição da hiperalgesia promovida pela administração intraplantar de endotoxina, reforçando o envolvimento das MMPs no desenvolvimento da dor inflamatória (TALHOUK e cols., 2000). Similarmente, os resultados deste trabalho mostram que o tratamento com doxiciclina, inibidor inespecífico para MMPs, foi capaz de bloquear a alodinia mecânica bem como a hiperalgesia orofacial promovidas pela administração intraarticular de CFA. Assim, estes achados suportam o envolvimento das MMPs expressas no sistema nervoso nos processos inflamatórios, bem como sua colaboração, particularmente, na expressão da sensibilidade dolorosa.

Nos últimos anos, os antibacterianos da classe das tetraciclinas, incluindo doxiciclina e minociclina, têm atraído a atenção da comunidade científica devido à sua habilidade de inibir as atividades de MMPs, tais como colagenase e gelatinase, independentemente de sua ação antimicrobiana (RYAN e cols., 1996). A doxiciclina é assim, um inibidor de amplo espectro da expressão de MMPs e tem sido usada para tratar diversas condições relacionadas com o excesso de atividades de MMP. Ainda, é estabelecido na literatura que a doxiciclina pode penetrar a barreira hemato-encefálica por suas propriedades lipofílicas (JANTZIE e cols., 2005). De fato, diversos trabalhos demonstram o efeito da doxiciclina como potente inibidor de MMP-2 e MMP-9 (FIOTTI e cols. 2009; LEE e cols. 2004; WOJTOWICZ-PRAGA e cols. 1997). Considerando estes aspectos, pode-se sugerir que no presente trabalho, o uso da doxiciclina promoveu bloqueio das MMP-2 e MMP-9, as quais foram evidenciadas em maior expressão no gânglio trigeminal durante o desenvolvimento da inflamação intraarticular, e desta forma, ocorreu redução da alodinia mecânica e da hiperalgesia orofacial. Entretanto, os resultados presentes mostram que a doxiciclina não reduziu o comportamento nociceptivo observado na primeira fase do teste da formalina orofacial 
(Figura 12B). É possível sugerir que considerando a formalina $2 \%$ um estímulo altamente irritante, agudo, o qual estimula diretamente os nociceptores de forma intensa, o bloqueio das MMPs não interfere neste processo sensorial. Em adição, considerando que a segunda fase do teste está associado com a resposta inflamatória decorrente da administração da formalina, e que o tratamento com inibidor de MMP interfere com os mecanismos inflamatórios é possível que neste caso, o tratamento com doxiciclina seja eficaz na redução da hiperalgesia, como demonstrado os resultados obtidos.

De fato, vários estudos idicam que as tetraciclinas podem estabelecer um atraso na progressão das lesões de cartilagem em modelos animais de osteoartrite (BRI e cols., 1998; YU e cols., 1992). Ainda, estudos clínicos mostraram que pacientes tratados com doxiciclina apresentaram reduzidas quantidades de colagenase e gelatinase (SMITH e cols., 1996). Como mecanismo, tem sido sugerido que o efeito inibitório sobre as MMPs ocorre a nível pós-translacional fundamentado na capacidade das tetraciclinas de quelar íons metálicos bivalentes $\mathrm{Ca}^{2+}$ e $\mathrm{Zn}^{2+}$, os quais são essenciais para a atividade das MMPs e/ou para sua estabilidade estrutural (RYAN e cols., 1996, SMITH e cols., 1996).

Considerando ainda o efeito da doxiciclina sobre as MMPs no tecido neural, Lee e cols. (2009) demonstraram que a inibição da MMP-9, pela administração prévia de doxiciclina, reduziu os danos cerebrais causados por isquemia cerebral transitória em camundongos. Neste estudo, utilizando técnicas de zimografia em gel e zimografia in situ, observou-se redução tanto da expressão como na atividade gelatinolítica desta MMP. Os autores sugerem, que a doxiciclina pode fornecer neuroproteção contra a isquemia cerebral global, uma vez que reduz a degradação da laminina perineuronal através da inibição da atividade de MMP-9.

Em resumo, os resultados do presente trabalho demonstram que a administração de CFA intraarticular bilateral na ATM promove alodinia mecânica e hiperalgesia 
orofacial. A alteração da sensibilidade mecânica e nociceptiva é dependente da expressão de MMPs, desde que o bloqueio com inibidor inespecífico, doxiciclina, bloqueou a alodinia mecânica e a segunda fase do teste da formalina orofacial. É possível que as MMPs, em particular, a MMP-2 e MMP-9 estejam envolvidas no desenvolvimento da resposta inflamatória intraarticular considerando que há aumento significativo da expressão e da atividade destas MMPs no gânglio trigeminal. Ainda, pode-se sugerir distinto envolvimento destas gelatinases no processo inflamatório, ou seja, a MMP-9 apresenta-se em maior quantidade na fase inicial, 1 e 3 dias após o início do processo inflamatório. Em contraste, a MMP-2 estaria correlacionada com a manutenção desta resposta inflamatória, tendo sua expressão aumentada iniciando-se 3 dias após a administração do CFA intraarticular, e mantendo-se em maiores quantidades 7 e 10 dias após. 
Fundamentado nos resultados obtidos neste trabalho, podem ser sumarizadas as seguintes conclusões:

- O CFA administrado na região das ATMs foi capaz de produzir resposta inflamatória local promovendo alodinia mecânica e hiperalgesia orofacial, evidenciados pela redução do limiar do reflexo de retirada de cabeça após a aplicação de um estímulo mecânico inócuo, e no teste da formalina orofacial.

- O desenvolvimento da inflamação temporomandibular pela administração de CFA aumentou a expressão das metaloproteinases MMP-2 e MMP-9 no gânglio trigeminal. Ainda, a expressão de MMP-9 é maior nos estágios iniciais do processo inflamatório ( $1^{\circ}$ e $3^{\circ}$ dia), enquanto que a expressão de MMP-2 está mais relacionada com a fase tardia desta resposta, $\left(3^{\circ}, 7^{\circ}, 10^{\circ}\right.$ dias $)$.

- Atividade gelatinolítica, avaliada pela técnica da zimografia in situ, está aumentada no gânglio trigeminal durante a todo o período avaliado, ou seja, 1, 3, 7 e 10 dias após o início do processo inflamatório.

- A doxiciclina, inibidor inespefício das MMPs, reduziu a alodinia mecânica, bem como a hiperalgesia orofacial induzidos pela administração intraarticular de CFA bilateralmente nas ATMs de ratos. 
AGUGGIA, M., BASBAUM, A. I., JESSEL, T. M. Neurophysiology of pain. Neurological Sciences, 24 (2), 57 - 60, 2003.

BASBAUM, A. I., JESSEL, T. M. The perception of pain. In: KANDEL, E. R., SCHWARTZ, J. H., JESSEL, T. M. The Principles of Neural Science, New York: McGraw-Hill, 472-791, 2000.

BEREITER, D. A., BEREITER, D. F., RAMOS, M. Vagotomy prevents morphineinduced reduction in Fos-like immunoreactivity in trigeminal spinal nucleus produced after TMJ injury in a sex-dependent manner. Pain, 96: 205-213, 2002.

BIRKEDAL-HANSEN, H. Role of cytokines and inflammatory mediators in tissue destruction. J Periodontal Research. 28:500-10, 1993.

BRANDÃO, M. L. Psicofisiologia. 2a ed., Editora Atheneu, São Paulo, 197, 1995.

BRI, E., LEI, W., SVENSSON, O., CHOWDHRURY, M., MOAK, S.A., GREENWALD, R. A. Effect of an inhibitor of matrix metalloproteinases on spontaneous osteoarthritis in guinea pigs, Adv. Dent. Res. 12: 82- 85. 1998.

CAMPOS, R. O. P., ALVES, R. V., FERREIRA, J., KYLE, D. J., CHAKRAVARTY, S., MAVUNKEL, B. J., CALIXTO, J. B. Oral antinociception and oedema inhibition produced by NPC 18884, a non-peptidic bradykinin B2 receptor antagonist. Naunyn Schmiedebergs Arch. Pharmacology. Berlin, 360 (3): 278-286, 1999.

CARLSSON, G. E., DEBOEVER, J. A. Epidemiologia. Disfunção da Articulação Temporomandibular e dos Músculos da Mastigação. São Paulo: Livraria Santos, 159-70, 2000.

CARLESSON, J., KOGNER, P., BILEVICIUTE, I., THEODORSSON, E., APPELGREN, A., APPELGREN B., KOPP, S., LUNDEBERG, T. Effects of capsaicin in temporomandibular joint arthritis in rats. Arch of Oral Biology. 42: 869-876, 1997. 
CATERINA, M. J., JULIUS, D. Sense and specificity: a molecular identy for nociceptors. Curr Opin Neurobiol., 9: 525-530, 1999.

CHANDLER, S., COATES, R., GEARING, A., LURY, J., WELlS, G., BONE, E. Matrix metalloproteinases degrade myelin basic protein. Neuroscience. Lett. 201: 223-226, 1995.

CHANG, C., WERB, Z. The many faces of metalloproteases: cell growth, invasion, angiogenesis and metastasis. Trends Cell Biology. 11(11): 37-43, 2001.

CHATTOPADHYAY, S., MYERS, R. R., JANES, J., SHUBAYEV, V. Cytokine regulation of MMP-9 in peripheral glia: Implications for pathological processes and pain in injured nerve. Brain Behavior Immunology. 21: 561- 568, 2007.

ClAVElOU, P., PAJOT, J., DALlEL, R., RABOISSON, P. Application of the formalin test to the study of orofacial pain in rat. Neuroscience. Lett. 103: 349-353, 1989.

COLLINS, T. Acute and chronic inflammation. In: COTRAN, R.S.; KUMAR, V.; COLLINS, T (Eds.). Robbins pathologic basis of disease. Philadelphia: Saunders, 6th ed., 50-88, 1999.

CORTELLI, P., PIERANGELI, G. Chronic pain-autonomic interactions. Neurological Sciences, 24(2): 68-70, 2003.

COSTA, L.,F.,M., GUIMARÃES, J. P., CHAOBAS, A. Prevalência de distúrbios da articulação temporo-mandibular em crianças e adolescentes brasileiros e sua relação com má-oclusão e hábitos parafuncionais: um estudo epidemiológico transversal Parte II: distúrbios articulares e hábitos parafuncionais. Jornal Brasileiro de Ortodontia \& Ortopedia Facial. 9 (50): 162-169, 2004.

COUGHLAN, A. R., ROBERTSON, D. H., BENNETT, D., MAY, C., BEYNON, R. J., CARTER, S. D. Matrix metalloproteinases 2 and 9 in canine rheumatoid arthritis. Vet Rec. 143(8):219-23, 1998. 
DUBNER, R. Basic mechanisms of pain associated with deep tissues. Can. J. Physiol. Pharmacol. 69: 607-609, 1991.

DUBNER, R., REN, K. Brainstem mechanisms of persistent pain following injury. Journal of Orofacial Pain. 18(4): 299-305. 2004.

DUBRUL, E. The craniomandibular articulation. In: Sicher's Oral Anatomy. St Louis: Mosby, $7^{\text {th }}$ ed, $147-209,1980$.

DZWONEK, J., RYLSKI, M., KACZMAREK, L. Matrix metalloproteinases and their endogenous inhibitors in neuronal physiology of the adult brain. Federation of European Biochemical Societies. 567(1): 129-35, 2004.

FAVERO, K. Disfunções da articulação temporomandibular: Uma visão etiológica e terapêutica multidisciplinar. Dissertação (Mestrado) - CEFAC: Centro de Especialização em Fonoaudiologia Clínica Motricidade Oral. São Paulo, 1999.

FIGUEREDO, C. M., CRISPINO, A. F., TINOCO, E. M. B. Níveis elevados de metaloproteinase da matriz-9 em sítios com destruição tecidual de pacientes com periodontite crônica generalizada. R. Clin. Med. Biol. 2(1): 40-47, 2003.

FIOTTI, N., Altamura, N., Moretti, M., Wassermann, S., Zacchigna, S., Farra, R. Term Effects of Doxycycline on Matrix Metalloproteinases 2 and 9. Cardiovasc Drugs Ther 23: 153-159, 2009.

FOLGUERAS, A. R. Matrix metalloproteinases in cancer: from new functions to improved inhibition strategies. Int. J. Dev. Biol, 48: 411-424, 2004.

GAUDIN, P., RAZAKABOAY, M., SURLA, A., BERTHIER, S., FAUCONNIER, J., MOREL, F., PHELIP, X. A study of metalloproteinases in fifty joint fluid specimens. Rev Rhum Engl. 64(6): 375-81, 1997.

GOULET, L. P.; LAVIGNE, G. J.; LUND, J. P. Jaw positioning prevalence among French speaking Canadian in Quebéc and relates symptoms of temporomandibular disorders. J Dental Research. 74: 1738-1744, 1995. 
GRABOW, T. S. \& DOUGHRTY, P. M. Cervicomedullary intrathecal injection of morphine produces antinociception in the orofacial formalin test in the rat. Anestesiology. 95: 1427-1434, 2001.

GUO, W., ZOU S., GUAN Y., IKEDA, T., TAL, M., DUBNER, R., REN, K. Tyrosin phosphorylation of the NR2B subunit of the NMDA receptor in the spinal cord during the development and maintenance of inflammatory hyperalgesia. Journal Neuroscience. 22: 6208-6217, 2002.

HARPER, R. P., KERINS, C. A., TALWAR, R., SPEARS, R., CARLSON, D. S.; MCLNROSH, J.E. Meal pattern analyses in response to temporamandibular joint inflammation in the rat. Journal Dental Reearch. 79: 1704-1711, 2000.

HARPER, R. P., KERINS, C. A., MCLNROSH, J. E., SPEARS R., BELLINGER, L. L. Modulation of the inflammatory response in the rat TMJ with increasing doses of complete Freund's adjuvant. J Osteoarthritis Res Soc International. 9: 619-624, 2001.

HOWARD, E. W.; BULLEN, E. C.; BANDA, M. J. Preferential inhibition of 72- and 92-kDa gelatinases by tissue inhibitor of metalloproteinases-2. J. Biol. Chem. 266 (20):13070-5; 1991.

IMBE, H., REN, K. Orofacial deep and cutaneous tissue inflammation differentially upregulates preprodynorphim mRNA in the trigeminal and paratrigeminal nuclei of the rat. Mol Brain Res., 37: 87-97, 1999.

IMBE, H., IWATA, K., ZHOU. Q. Q., ZOU, S., DUBNER, R., REN, K. Orofacial deep and cutaneous tissue inflammation and trigeminal neuronal activation implications for persistent temporomandibular pain. Cells Tiss Org. 169: 238-247, 2001.

ISHIMARU, J. I., OGUMA, Y., GOSS, A. N. Matrix metalloproteinase and tissue inhibitor of metalloproteinase in serum and lavage synovial fluid of patients with temporomandibular joint disorders. Br J Oral Maxillofac Surgery. 38: 354-359, 2000. 
IWATA, K., TASHIRO, A., TSUBOI, Y., IMAI, T., SUMINO, R., MORIMOTO, T., DUBNER, R., REN, K. Medullary dorsal horn neuron activity in rats with persistent temporomandibular joint and perioral inflammation. J Neurophysiol., 82: 1244$1253,1999$.

JANTZIE, L. L., CHEUNG, P. Y., TODD, K. G. Doxycycline reduces cleaved caspase3 and microglial activation in an animal model of neonatal hypoxia-ischemia. $\mathrm{J}$. Cereb. Blood Flow Metab. 25: 314-324, 2005.

JOVANOVIC, D. V., Di Battista, J. A., Martel-Pelletier. J., Jolicoeur, F. C.; He, Y., Zhang, M., Mineau, F., Pelletier, J. P. IL-17 stimulates the production and expression of proinflammatory cytokines, IL-beta and TNF-alpha, by human macrophages. J Immunol. 160(7):3513-21. 1998.

KACZMAREK, L., LAPINSKA-DZWONEK, J., SZYMCZAK, S. Matrix metalloproteinases in the adult brain physiology: a link between c-Fos, AP-1 and remodeling of neuronal connections? EMBO J. 21(24): 6643-8, 2002.

KAWASAKI, Y., XU, Z., WANG, X., PARK, J. Y., ZHUANG, Z., TAN, P., GAO, Y. J.; ROY, K., CORFAS, G., LO, E. H., JI, R. Distinct roles of matrix metalloproteases in the early- and latephase development of neuropathic pain. Nat Med; 14(3): 331-336, 2008.

KOBAYASHI, H., CHATTOPADHYAY, S., KATO, K., DOLKAS, J., KIKUCHI, S., MYERS, R. R., SHUBAYEV, V. MMPs initiate Schwann cell-mediated MBP degradation and mechanical nociception after nerve damage. Molecular and Cellular Neuroscience 39: 619-627, 2008.

KOMORI, K., NONAKA, T., OKADA, A., KINOH, H., HAYASHITA-KINOh, H., YOSHIDA, N., e cols. Absence of mechanical allodynia and Abeta-fiber sprouting after sciatic nerve injury in mice lacking membrane-type 5 matrix 
metalloproteinase. Federation of European Biochemical Societies. 557: 125-128. 2004.

KRANE, S. M. Clinical importance of metalloproteinases and their inhibitors. Ann NY Acad Sci. 732: 1-10, 1994.

KUBOTA, T., KUBOTA, E., MATSUMOTO, A., KAWAI, Y., SAITO, H., MIKUNITAKAGAKI, Y., SATO, S. Identification of matrix metalloproteinases (MMPs) in synovial fluid from patients with temporomandibular disorder. Eur J Oral Sci. 106: 992-998, 1998.

LAM, D. K., SESSLE, B. J., CAIRNS, B. E., HU, J. W. Neural mechanisms of temprormandibular joint and masticatory muscle pain: a possible role for peripheral glutamate receptor mechanisms. Pain Res Manag. 10: 145-152, 2005.

LEE, S. R., TSUJI, K., LEE, S. R., LO, E. H. Role of matrix metalloproteinases in delayed neuronal damage after transient global cerebral ischemia. J. Neurosci. 24: 671-678, 2004.

LEONE, L., DE STEFANO, M. E., DEL SIGNORE, A., PETRUCCI, T. C., PAGGI, P. Axotomy of sympathetic neurons activates the metalloproteinase-2 enzymatic pathway. J. Neuropathol. Exp. Neurol. 64: 1007-1017, 2005.

LOESER, J. D.; MELZACK, R. Pain: an overview. Lancet. 353: 1607-1609, 1999.

LUND, J. P., LAVIGNE, G. J., DUBNER, R.; SESSLE, B J. Dor orofacial - da ciência básica à conduta clínica. 1ª ed. Quintessence, Rio de Janeiro, Brasil, 2002.

MACFARLANE, T. V., BLINKHORN, A. S., DAVIES, R. M., KINCEY, J., WORTHINGTON, H. V. Orofacial pain in the community: prevalence and associated impact. Comm Dent Oral Epidemiol. 30(1): 52-60, 2002.

MADEIRA, M. C. - Anatomia da face: Bases anatomofuncionais para a prática odontológica. São Paulo, Sarvier, 1995. 
MAMET, J., LAZDUNSKI, M., VOILLEY, N. How nervy grown factor drives physiological and inflammatory expressions of acid-sensing in channel 3 in sensory neurons. J Biol Chem. 278(48): 48907-48913, 2003.

MCCAWLEY, L. J., MATRISIAN, L. M. Matrix metalloproteinases: they are not just for matrix anymore! Curr Opin Cell Biol. 13: 534-540, 2000.

MEIKEL, M. C. Remodeling. In: The temporomandibular joint: a biological basis for clinical practice. Philadelphia: Saunders, $4^{\text {th }}$ ed. 93-107, 1992.

MERSKEY, H., BOGDUK, N. Classification of chronic pain: description of chronic pain syndromes and definitions of pain terms. Seattle:IASP Press, 1994.

MILLAN, M. J. The induction of pain: an integrative review. Prog Neurobiol. 57(1): 1$164,1999$.

MIZUI, T., ISHIMARU, J.I., MIYAMOTO, K., KURITA, K. Matrix metalloproteinase2 in synovial lavage fluid of patients with disorders of the temporomandibular joint. Br J Oral Maxillofac Surg. 39: 310-314, 2001.

MURPHY, G., WILLENBROCK, F. Tissue inhibitors of matrix metalloendopeptidases. Methods Enzymol. 248: 496-510, 1995.

NAGASE, H., WOESSNER, J. F. JR., Matrix metalloproteinases. J. Biol. Chem. 274(31): 21491-21494, 1999.

NAVARRO, S. Start the new year with proper oral health care. School Nurse News. 23(1): 8-9, 2006.

OKESON, J.P. Dor orofacial: guia para avaliação, diagnóstico e tratamento. São Paulo (SP): Santos Livraria; 1998.

OKESON, J. P., ATTANASIO, R., MOHL, N. D. Temporomandibular disorders: past, present, and future. J Craniomandib Disord. Spring. 6(2): 103-6, 1992. 
OLIVEIRA, M. C., PARADA, C. A., VEIGA, M. C., PODRIGUES, L. R., BARROS, S. P., TAMBELI, C. H. Evidence for the involvement of endogenous ATP and P2X receptors in TMJ pain. Eur J Pain, 9: 87-93, 2005.

PAGGI P., DE STEFANO, M. E., PETRUCCI, T. C. Synaptic remodeling induced by axotomy of superior cervganglion neurons: Involvement of metalloproteinase-2. Journal of Physiology - Paris. 99: 119-124, 2006.

PASQUALE, C. P., MARTINS, M. A., BOZZA, P. T., SILVA, P. M., FARIA NETO, H. C., PIRES, A. L., CORDEIRO, R. S. Bradykinin induces eosinophil accumulation in rat pleural cavity. Int. Arch. Allergy Immunol., Basel. 95(2-3): 244-247, 1991.

PÉLISSIER, J., PETIOT, S., BÉNAÏM, C., ASENCIO, G. Treatment of neurogenic heterotopic ossifications (NHO) in brain injured patients: review of literature. Ann Readapt Med Phys. 45(5): 188-97, 2002.

PEREIRA, A. C., CARMO, E. D., SILVEIRA, V. A. C., ROSA, L. E. B. O papel das MMP-2 e -9 no desenvolvimento do carcinoma epidermóide. Revista Brasileira de Cancerologia. 52(3): 257-262, 2006.

PESQUERO, J. B., ARAUJO, R. C., HEPPENSTALl, P. A., STUCKY, C. L., SILVA Jr, J. A., WALTher, T., OLIVEIRA, S. M., PESQUERO, J. L., PAIVA, A. C. M., CALIXTO, J. B., LEWIN,G. R., BADER, M. Hypoalgesia and altered inflammatory responses in mice lacking kinin B1 receptors. Proc. Natl. Acad. Sci. USA, Washington. 97(14): 8140-8145, 2000.

PINTO, L. G., CUNHA, T. M., VIEIRA, S. M., LEMOS, H. P., VERRI, W. A. JR, CUNHA, F. Q., FERREIRA, S. H. IL-17 mediates articular hypernociception in antigen-induced arthritis in mice. Pain. 148(2): 247-56, 2010.

PROUD, D. \& KAPLAN, A. P. Kinin formation: mechanisms and role in inflammatory disorders. Annu. Rev. Immunol., Palo Alto. 6: 49-83, 1988. 
PURVES, D.; AUGUSTINE, G. J.; FITZPATRICK, D.; KATZ, L.C.; LAMANTIA, A.-S.; MCNAMARA, J. O.; WILLIAMS, S. M. Neuroscience. $2^{\text {nd }}$ ed. Sunderland (MA): Sinauer Associates, 2001.

REN, K., DUBNER, R. An inflammation/hyperalgesia model for the study of orofacial pain. J Dent Res. 75: 217, 1996.

RIZZI, E., CASTRO, M. M., FERNANDES, F., BARBOSA, F., ARISI, G. M., GARCIA-CAIRASCO, N., BENDHACK, L. M., TANUS-SANTOS, J. E., GERLACH, R. F. Evidence of early involvement of matrix metalloproteinase-2 in lead-induced hypertension. Arch Toxicol. 83(5): 439-49, 2009.

RO, J. Y. Contribution of peripheral NMDA receptors in craniofacial muscle nociception and edema formation. Brain Research. 979: 78-84, 2003.

ROVERONI. R. C., PARADA, C. A.; VEIGA, M. C., TAMBELI, C. H. Development of a behavioral model of TMJ pain in rats: the formalin test. Pain. 94: 185-191, 2001.

RYAN, M. E., GREENWALD, R. A., GOLUB, L. M. Potential of tetracyclines to modify cartilage breakdown in osteoarthritis, Curr. Opin. Rheumatol. 8: 238- 247, 1996.

RYAN, G. B. \& MAJNO, G. Acute inflammation. Am. J. Pathol. Philadelphia. 86(1): 184-271, 1977.

SALTER, M. W. Cellular neuroplasticity mechanisms mediating pain persistence. J. Orofacial Pain. 18(4): 318-324, 2004.

SCHUTZ, T. C. B., ANDERSEN, M. L.; TUFIK, S. Sleep alterations in an experimental orofacial pain model in rats. Brain Research, 993: 164-171, 2003.

SERRA, J. Overview of neuropathic pain syndromes [new advances in the treatment of neuropathic pain]. Acta Neurol Scand. 100(73): 7-11, 1999.

SHIGEMATSU, S., ISHIDA, S., GUTE, D. C., KORTHUIS, R. J. Concentration dependent effects of bradykinin on leukocyte recruitment and venular 
hemodynamics in rat mesentery. Am. J. Physiol. Washington. 277(2): 152-160, 1999.

SHINMEI, M., MASUDA, K., KIKUCHI, T. The role of cytokines in chondrocyte mediated cartilage degradation. J Rheumatology. 18: 32-34, 1989.

SMITH, G. N., BRANDT, K. D., HASTY, K. A. Activation of recombinant human neutrophil procollagenase in the presence of doxycycline results in fragmentation of the enzyme and loss of enzyme activity, Arthritis Rheum. 39: 235-244, 1996.

SORSA, T., TJÃDERHANE, L, SALO, T. Matrix metalloproteinases in oral diseases. Oral Diseases. 10: 311-318, 2004.

SOUZA, A. L. S., MOREIRA, F. A., ALMEIDA, K. R., BERTOLLO, C. M., COSTA, K. A., COELHO, M. M. In vivo evidence for a role of protein kinase C in peripheral nociceptive processing. Br. J. Pharmacol., London. 135(1): 239-247, 2002.

SOUZA, A. P., TREVILATTO, P. C., SCAREL-CAMINAGA, R. M., BRITO, R. B., LINE, S. R. MMP-1 promoter polymorphism: association with chronic periodontitis severity in a Brazilian population. J Clin Periodontol. 30(2):154-8, 2003.

SRINIVAS, R., SORSA, T., TJADERHANE, L., NIEMI, E., RAUSTIA, A., PERNU, H., et al. Matrix metalloproteinases in mild and severe temporomandibular joint internal derangement synovial fluid. Oral Surg Oral Med Oral Pathol Oral Radiol Endodontic. 91: 517-24, 2001.

STEIN, C., MILLAN, M. J., HERZ, A. Unilateral inflammation of the hindpaw in rats as a model of prolonged noxious stimulation: alterations in behavior and nociceptive thresholds. Pharmacol Biochem Behavior. 31: 445-451, 1988

STAMENKOVIC, I. Matrix metalloproteinases in tumor invasion and metastasis. Semin Cancer Biology. 10(6): 415-33; 2000. 
TALHOUK, R. S. HAJJAR, L., ABOU-GERGI, R., SIMAA`N, C. J., MOUNEIMNE, G., SAADE, N. E., SAFIEH-GARABEDIAN, B. Functional interplay between gelatinases and hyperalgesia in endotoxin-induced localized inflammatory pain. Pain. 84: 397-405, 2000.

TANAKA, A., KUMAGAI, S., KAWASHIRI, S., TAKATSUKA, S., NAKAGAWA, K., YAMAMOTO, E. e cols. Expression of matrix metalloproteinase-2 and -9 in synovial fluid of the temporomandibular joint accom- panied by anterior disk displacement. J Oral Pathol Med. 30: 59-64, 2001.

TING, A. L., KAI, A. L., FEI-YU A. Z., ZHEN-KANG A. Z., ALAN R. L. B., KAIYUAN, F. Dissociation of spinal microglia morphological activation and peripheral inflammation in inflammatory pain models. J Neuroimmune. 192: 40-48, 2007.

VAILLANT, C., DIDIER-BAZES, M., HUTTER, A., BELIN, M. F. THOMASSET, N. Spatiotemporal expression patterns of metalloproteinases and their inhibitors in the postnatal developing rat cerebellum. J. Neuroscience. 19: 4994-5004, 1999.

VASCONCELLOS, H. A. Músculos da mastigação e da coluna cervical: estudo anatomofuncional aplicado. Oral.Med. 16(4): 13-17, 1989.

WOJTOWICZ-PRAGA, S. M., DICKSON, R. B., HAWKINS, M. J. Matrix metalloproteinase inhibitors. Invest New Drugs. 15: 61-75, 1997.

WU, Y. W., BI, Y. P., KOU, X. X., XU, W., MA, L. Q., WANG, K. W., GAN, Y. H., MA, X. C. 17B Estradiol enhanced allodynia of inflammatory temporomandibular joint through upregulation of hippocampal TRPV1 in ovariectomized rats. The Journal of neuroscience, 30(26): 8710-8719, 2010.

YAMASAKI, Y., REN, K., SHIMADA, M., IWATA, K. Modulation of paratrigeminal nociceptive neurons following temporomandibular joint inflammations in rats. Exp Neurol. 214(2): 209-218, 2008. 
YOSHIDA, H, YOSHIDA, T., IIZUKA, T., SAKA-KURA, T., FUJITA S. The localization of matrix metalloproteinase-3 and tenascin in synovialmembrane of the temporomandibular joint with internal derangement. Oral Disease. 5: 50-54. 2006.

YONG, V. W., POWER, C., FORSYTH, P., EDWARDS, D. R., "Metalloproteinases in biology and pathology of the nervous system, Nature Reviews Neuroscience.2(7): 502-511, 2001.

YU, L. P., SMITH, G. N., BRANDT, K. D., MYERS, S. L., O`CONNOR, B. L., BRANDT, D.A. Reduction of the severity of canine osteoarthritis by prophylactic treatment with oral doxycycline, Arthritis Rheum. 35: 1150-1159, 1992.

ZHOU, Q. Q., IMBE, H., DUBNER, R, REN, K. Persistent Fos protein expression after orofacial deep or cutaneous tissue inflammation in rats: implications for persistent orofacial pain. J Comp Neurol. 412: 276-291, 1999.

ZIEGLGANSBERGER, W.; BERTHELE, A.; TOLLE, T.L. Understanding neuropathic pain. CNS Spectrum 10(4): 289-308, 2005. 